\title{
On the Question of Zwitterionic Intermediates in the [3+2] Cycloaddition Reactions: A Critical Review
}

\author{
Radomir Jasiński ${ }^{1, *(1)}$ and Ewa Dresler ${ }^{2}$ \\ 1 Institute of Organic Chemistry and Technology, Cracow University of Technology, Warszawska 24, \\ 31-155 Cracow, Poland \\ 2 Łukasiewicz Research Network-Institute of Heavy Organic Synthesis “Blachownia”, Energetyków 9, \\ 47-225 Kędzierzyn-Koźle, Poland; ewa.dresler@icso.lukasiewicz.gov.pl \\ * Correspondence: radomir.jasinski@pk.edu.pl
}

Received: 9 November 2020; Accepted: 24 November 2020; Published: 26 November 2020

\begin{abstract}
New discoveries require a fundamental revision of the view on the mechanism of the 32CAreaction (according to the older nomenclature defined as 1,3-dipolar cycloaddition reactions). The view of the one-step, "concerted" mechanism of such processes developed in the 20-century is very popular today, both in academic literature and among organic chemists who do not specialize in such transformations. Meanwhile, more and more reports bring examples of reactions that clearly cannot be treated as processes without intermediates. However, these examples are documented very differently. In addition to comprehensive studies using many complementary research techniques, there are also reports in which the presence of intermediates in the cycloaddition environment is postulated on the basis of very unreliable premises. This review is an attempt at a critical analysis and systematization of data in the presented area.
\end{abstract}

Keywords: [3+2] cycloaddition; mechanism; zwitterionic intermediates

\section{Introduction}

The first case of [3+2] cycloaddition (32CA) was described in 1888 and relates to the reaction of carboethoxydiazomethane $\mathbf{1}$ with diethyl fumarate $\mathbf{2}$ [1]. This reaction produces an unsTable 3,4,5-tricarboethoxypyrazoline 3 of undetected stereo-configuration, which is spontaneously converted to 1,2,3-tricarboethoxycyclopropane 4 upon elimination of the nitrogen molecule (Scheme 1).

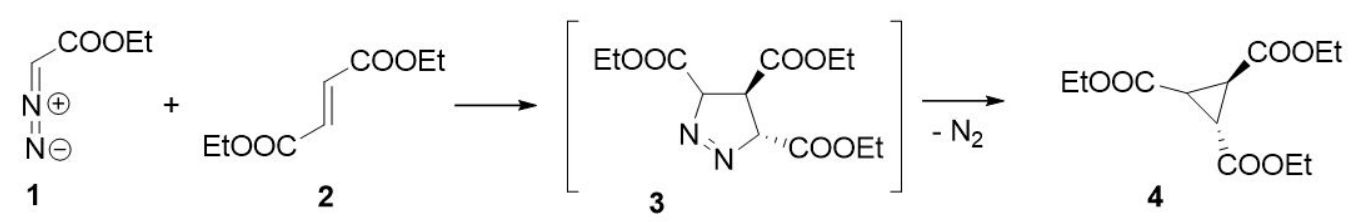

Scheme 1. The first historical example of 32CA reaction between carboethoxydiazomethane and dietyl fumarate.

According to the definition of Huisgen, which appeared more than half a century later [2], the basis of 32CA is the participation of compounds known then as 1,3-dipoles. Huisgen included among them, inter alia, nitrones, azomethyne ylides, carbonylylides, nitrile oxides, azides, diazomethane analogs, ozone, and many more. The mechanism of this type of transformation proposed by Huisgen $[2,3]$ assumed a synchronous circular shift of six $\pi$-electrons within a five-member transition state. As a result, simultaneously with breaking the existing $\pi$ bonds, two new $\sigma$ bonds would arise. A mechanism 
of this kind was called "concerted" and was generally recognized as valid regardless of additive structure (Scheme 2).

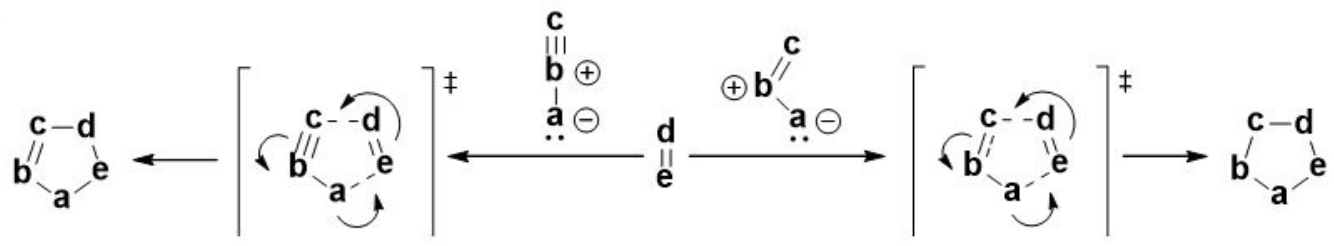

Scheme 2. Concerted mechanism of 32CA proposed by Huisgen.

For a long time, this view was considered the only correct one, despite numerous attempts to find cases of the mechanism deviating from the generally accepted dogma. To this day, it remains the only cycloaddition theory available in many academic textbooks [4,5]. The most vociferous debate on this subject took place with the participation of Huisen $[2,3,6,7]$ and Firestone, who postulated the presence of the diradical intermediate by converting addents into adducts [8-10] (Scheme 3).

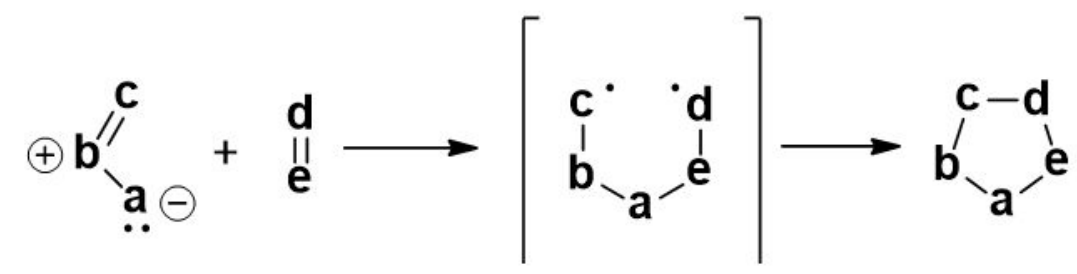

Scheme 3. Stepwise, biradical mechanism of 32CA proposed by Firestone.

However, examples clearly proving the existence of such intermediates were not found at that time. Yet not many years passed before Huisgen himself refuted his theory, defended with such great energy, publishing in 1986 the works [11,12], in which he proved beyond any doubt the stepwise nature of some 32CA processes involving sterically crowded tiocarbonyl ylides and extremely deficient alkenes. Another significant breakthrough came when Domingo showed [13] that not all compounds previously referred to as 1,3-dipoles can, in fact, be ascribed a 1,3-dipolar nature. Domingo defined them more universally as "three atom components" (TACs), and divided them into different groups differing in electronic structure, which, in turn, determines the type of reactivity in the cycloaddition process (Table 1) $[13,14]$. This made it necessary to replace the until recently common term "1,3-dipolar cycloaddition" with the more appropriate term [3+2] cycloaddition, referring to the number of atoms contributed by the reaction components to the ring being formed. This term is commonly used today.

Currently, taking into account the differences in the polarity of the 32CA components, these processes (similar to the Diels-Alder reactions) are generally classified into two groups: Polar and non-polar [13-15]. In both groups, these can be processes with synchronous and asynchronous formation of new bonds $\sigma$. The stepwise mechanism (Figure 1) will be the extreme case of the latter variant.

In this case, the first step in the reaction will be the formation of the labile acyclic intermediate. Since the possibility of rotation around the bond brought from the $2-\pi$-component to the target five-membered ring is unlocked within it, the stepwise process may be carried out with a partial or complete change of the substituent configuration. This, in turn, implies obvious effects in synthetic practice as manifested by limited stereo-selectivity. Hence, from a practical point of view, it is worth being able to recognize the conditions under which it is possible to force the 32CA mechanism stepwise. 
Table 1. Examples of different-type, nitrogen containing three atom components (TACs) according to Domingo classification [13].

\begin{tabular}{llll}
\hline & Nitrones & Nitrile ylides \\
\hline Pseudodiradical & Pseudoradical & Zwitterionic & Carbenoid \\
\hline Pdr-tpe & Reactivity: & & Cb-type \\
\hline
\end{tabular}

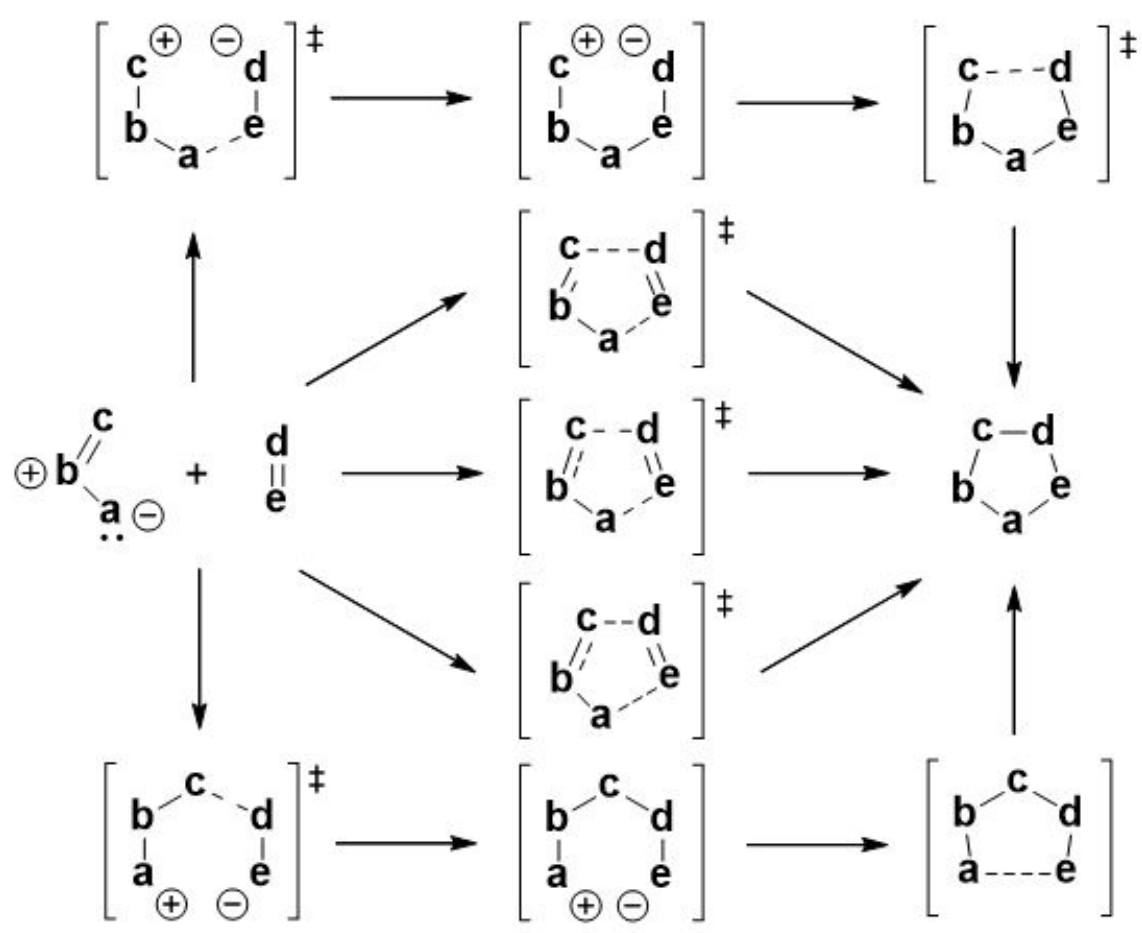

Figure 1. Theoretically possible cycloaddition mechanism in the light of degree bonds development.

There are a number of factors that may suggest a stepwise mechanism. As already mentioned, the existence of the zwitterionic intermediate may result in a loss of the stereospecificity of the reaction. Moreover, zwitterion conversion products may appear in the post-reaction mass. Another kind of information comes from kinetic research. It is known $[16,17]$ that zwitterionic reactions are sensitive to changes in the polarity of the environment and the nature of the substituent linked to the reaction centers. Moreover, the entropies of activation of such processes can be much lower than in the case of single-step reactions. Finally, the development of computational methods and the availability of high-powered computers offer the possibility of quantum-chemical modeling of reaction profiles, shedding light on the nature of critical structures of cycloaddition.

In recent years, this issue has enjoyed ceaseless interest among organic chemists. Therefore, in this paper, we decided to critically discuss the most important cases for which the zwitterionic, stepwise mechanism of 32CA was postulated. These studies were performed with respect to reactions involving 
the most common TACs, such as thiocarbonyl- and azomethine ylides, nitrones and their derivatives, nitrile $\mathrm{N}$-oxides, azides, and diazo compounds.

\section{TACs as Components of Stepwise 32CA Reactions}

\subsection{Thiocarbonyl Ylides}

The first reliably documented case of stepwise 32CA which follows the zwitterionic mechanism was described in 1986 by Huisgen and Mloston [12] (Scheme 4). The authors observed that in the case of reactions with sterically crowded thiocarbonyl ylides $\mathbf{5 a}$, $\mathbf{b}$ dimethyl 1,2-dicyanofumarate $\mathbf{6}$, both being adducts with the expected trans-configuration of substituents in the 3 and 4 positions of the heterocyclic ring $(\mathbf{1 0 a}, \mathbf{b})$, as well as the 3,4-cis configuration $(\mathbf{1 1 a}, \mathbf{b})$. Interestingly, identical pairs of products are formed in an analogous reaction involving dimethyl 1,2-dicyanomaleate 7 . Since there are no acid protons in positions 3 and 4 of the formed thiolates, the only explanation for the observed isomerization is the formation of zwitterion $\mathbf{8} \mathbf{a}, \mathbf{b}$ and $\mathbf{9 a , b}$ as an intermediate by reaction. Moreover, experimental studies have shown a significant influence on the stereo-selectivity of cycloaddition of the polarity of the solvent. Stepwise, the zwitterionic mechanism of the described 32CA is further confirmed by quantum chemical studies performed in the Houk group [18].

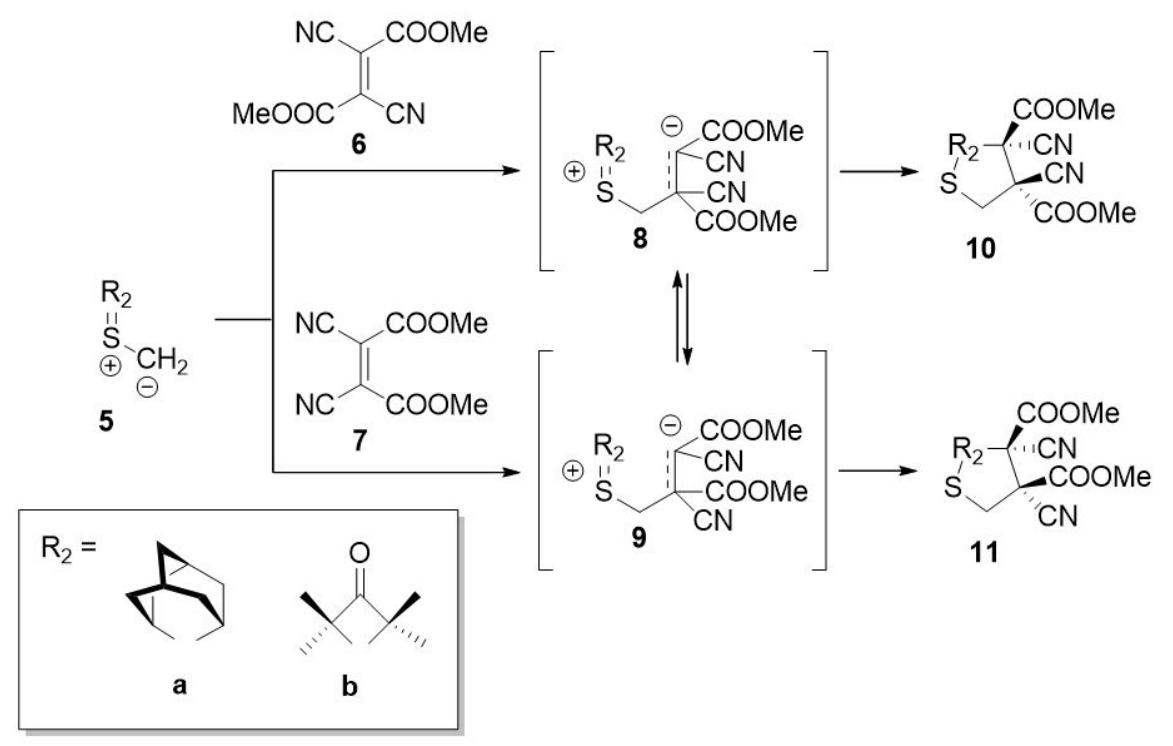

Scheme 4. Mechanism of 32CA of sterically crowded thiocarbonyloylides with 1,2-dicyanofumarate and dimethyl 1,2-dicyanomaleate.

On the other hand, in the course of a similar reaction involving 2,2,4,4-tetramethyl-3-thiocyclobutanone S-methylide $\mathbf{5 b}$ and tetracyanoethene 12, apart from the expected [3+2] cycloadduct, it forms an adduct [3+4] [11] (Scheme 5). Since [3+4] cycloadditions do not follow one-step mechanisms, the authors assumed that, in the course of the reaction, a zwitterionic intermediate may be formed and cyclized on competing pathways to 5- or 7-membered products. Such a mechanism can be considered credible in the light of the above-mentioned data on similar reactions involving dimethyl 1,2-dicyanofumarate 6 and dimethyl 1,2-dicyanomaleate 7. It is additionally confirmed by quantum chemical studies performed by Domingo [19].

Later studies showed that an analogous mechanism can be applied to a larger group of reactions involving thiocarbonyl ylides spatially crowded at one of the carbon atoms of the $>\mathrm{CSC}<$ fragment and 1,2-di(EWG)-1,2-dicyanoethenes [20-25]. Interestingly, in the case of reactions involving alkenes having $\mathrm{CF}_{3}$ groups on the double bond, the intermediates with a "bent" ketimine fragment can be isolated as stable links and identified by $\mathrm{X}$-ray analysis. 


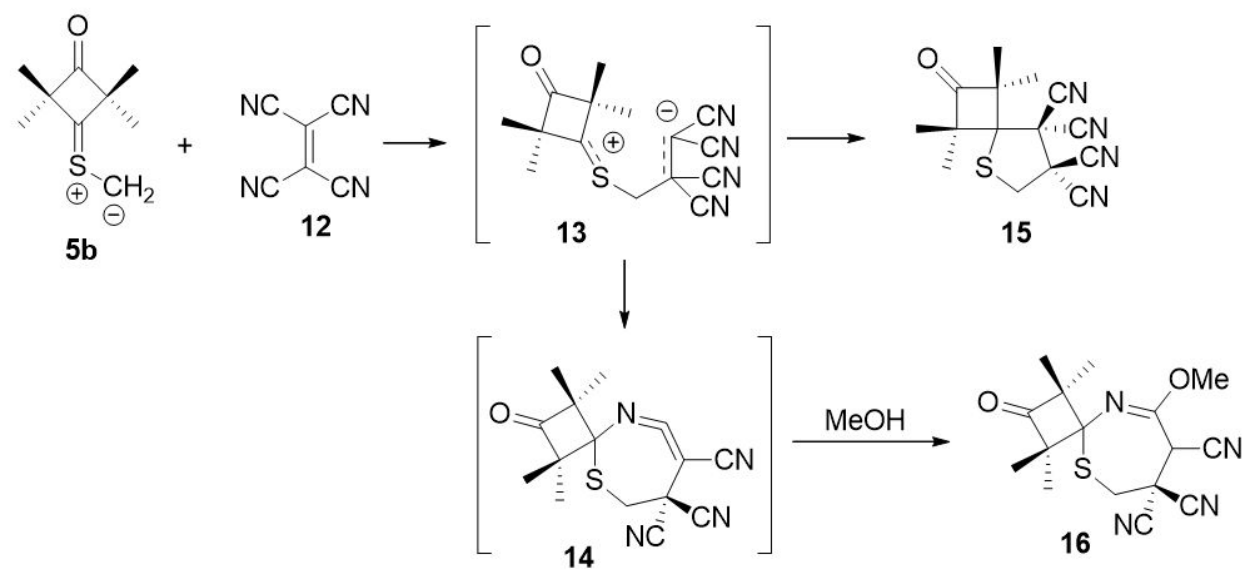

Scheme 5. Mechanism of 32CA of 2,2,4,4-tetramethyl-3-thiocyclobutanone S-methylide with tetracyanoethene.

2,2,4,4-tetramethyl-3-thiocyclobutanone S-methylide $\mathbf{5 b}$ was also tested as a component of the reaction with nitroethylene $\mathbf{1 7}$ (Scheme 6) [26]. In this reaction, in addition to the expected nitrothiolane, considerable amounts of polynitroethylene are formed. This gave rise to the conclusion that the first stage of the reaction is likely to be zwitterion formation, which on competing pathways can either cyclize to [3+2] cycloadduct 19 or initiate ionic polymerization of nitroethene. Such a scenario is confirmed by the recent comprehensive DFT studies [27,28], taking into account both the stage of zwitterion formation and its cyclization, as well as the molecular mechanism of polymerization leading to multi-nitro compounds.

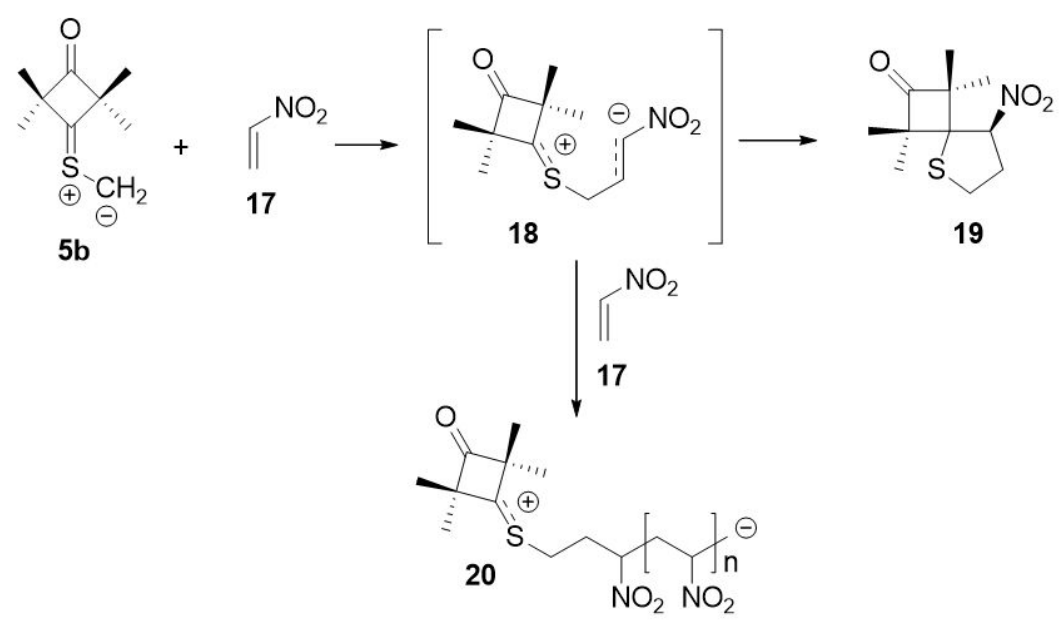

Scheme 6. Mechanism of 32CA of 2,2,4,4-tetramethyl-3-thiocyclobutanone S-methylide with nitroethene.

\subsection{Nitrones and Their Derivatives}

The first case of [3+2] nitrone (imine $\mathrm{N}$-oxides) cycloaddition where evidence was sought for a stepwise mechanism was the reaction of (Z)-C,N-diphenylnitrone (21) with 2,3-dialkyl substituted conjugated 1,3-dienes 22a-c [29,30] (Scheme 7). In all the cited cases, an adduct of the [3+4] type was identified in the post-reaction mass in addition to the expected isoxazolidines (23a-c and 25a-c), and the adducts, as we know, are not formed by one-step cycloaddition [31]. This gave rise to the assumption that a non-cyclic intermediate may occur through the conversion of the substrates to the product. However, the authors ruled out the zwitterionic nature of the hypothetical intermediate by examining the influence of environmental polarity on the course of the reaction. At the same time, 
they did not prove that this intermediate does indeed form. Recent DFT studies have shown [32] that, in fact, the investigated reactions are carried out without any acyclic intermediate, and the seven-membered product $\mathbf{2 6 a - c}$ is formed by isoxazolidine $\mathbf{2 3 a - c}$ rearrangement.

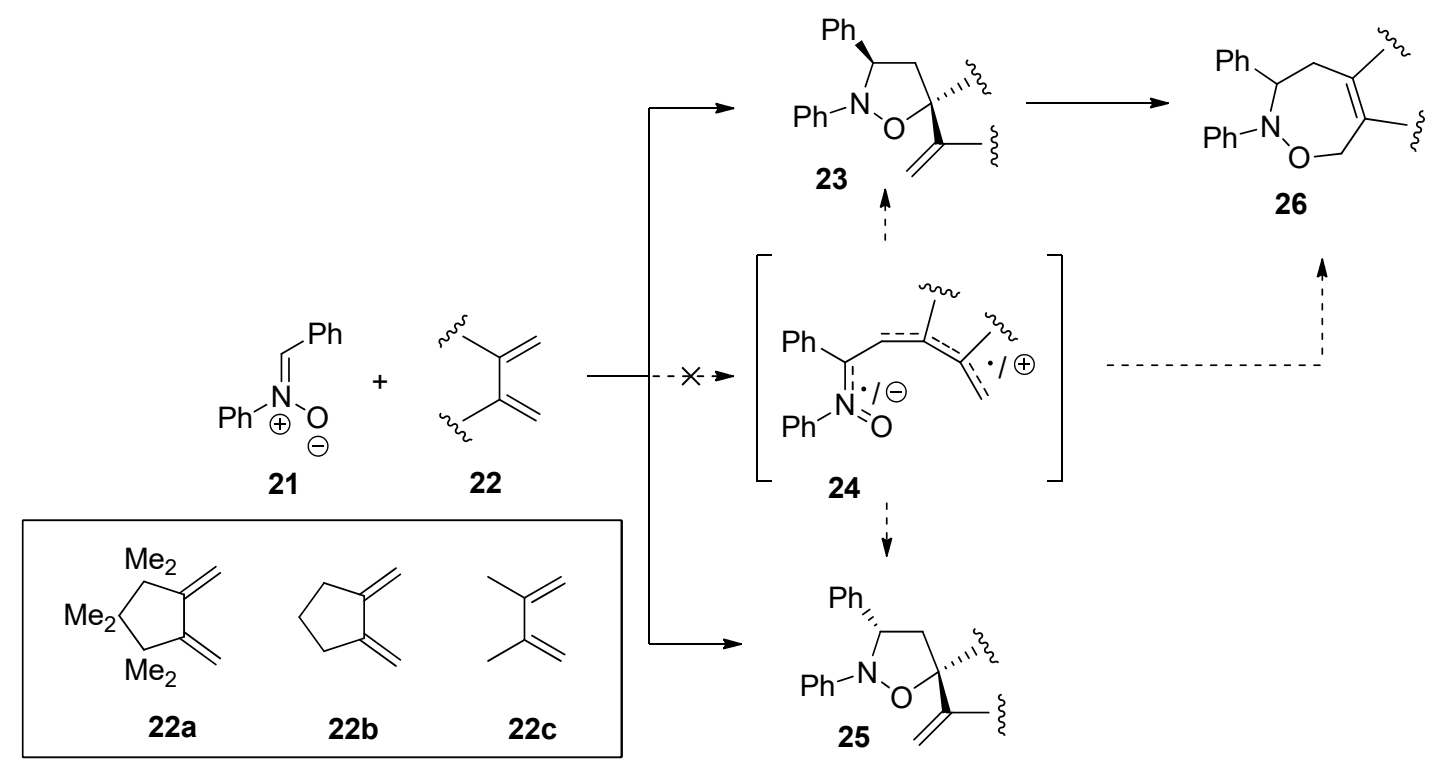

Scheme 7. Mechanism of 32CA of (Z)-C,N-diphenylnitrone with 2,3-dialkylsubstituted conjugated 1,3-dienes.

In turn, in the case of 32CA, with the participation of in situ generated C-arylonitrone $27 \mathrm{a}-\mathrm{c}$ with perfluorinated hexene 28 , next to the expected stereo-isomeric 3-aryl-4,4-trifluromethyl-5-fluoro-5-perfluoropentylisoxazolidines 29a-c and 31a-c, O-perfluoroalkyl oximes are formed (Scheme 8). This must be associated with the formation of the zwitterionic acyclic intermediate 30a-c. It remains an open question whether it is a common intermediate for the formation of [3+2] cycloadducts $29 \mathbf{a}-\mathbf{c}$ and $31 \mathbf{a}-\mathbf{c}$.

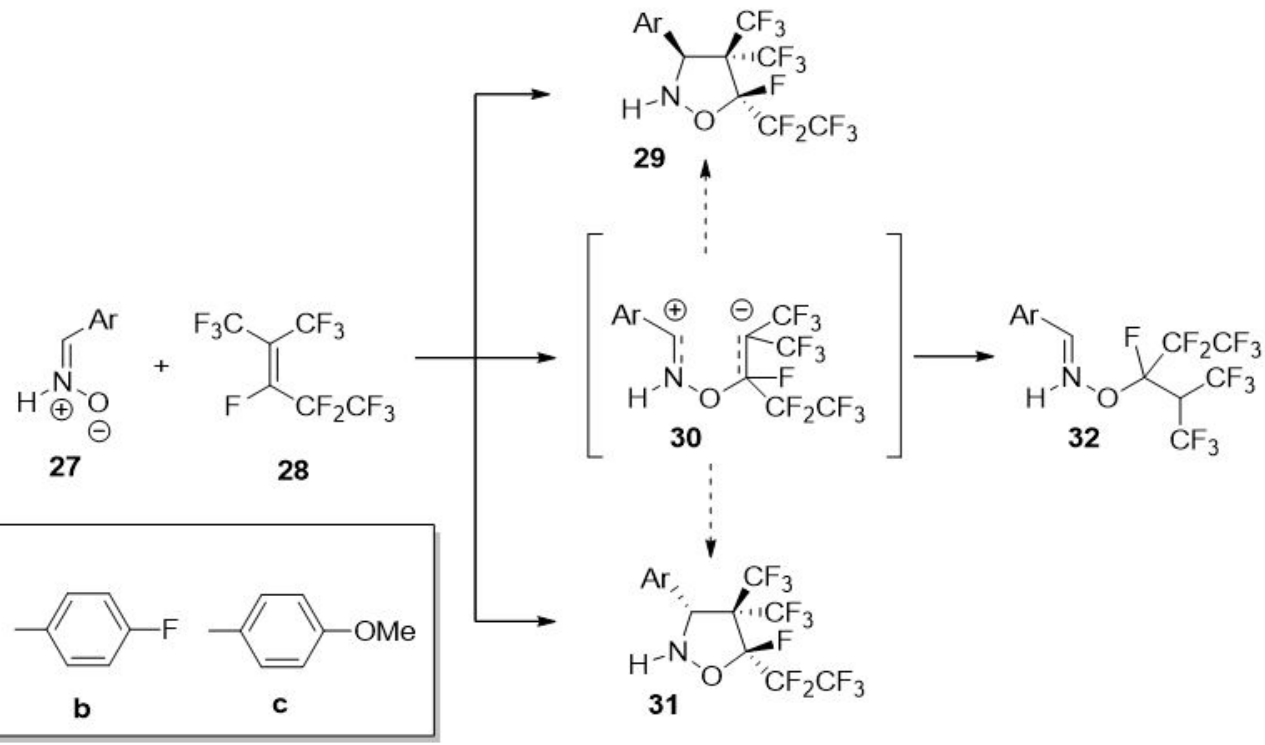

Scheme 8. Mechanism of 32CA of C-arylonitrone with perfluorinated hexene.

In the isomeric reactions of (E)- and (Z)-1,1,1,2,3-pentafluoro-3-phenylethenes 34a-c and 35a-c, mixtures of adducts with a configuration on the $\mathrm{C} 3$ and $\mathrm{C} 4$ atoms of the heterocyclic ring are always 
formed, which is identical to those added to alkene, and the reverse [33] (Scheme 9). As there are no acidic protons at these atoms that could stimulate the process of adduct isomerization, this fact implies the necessity to create an acyclic intermediate within which rotation around the $>\mathrm{C}(\mathrm{F})-\mathrm{CFF}\left(\mathrm{CF}_{3}\right)$ bond is possible. The existing stereo-chemical evidence for the stepwise mechanism of the analyzed 32CAis therefore identical to that in the case of thiocarbonyl ylides.
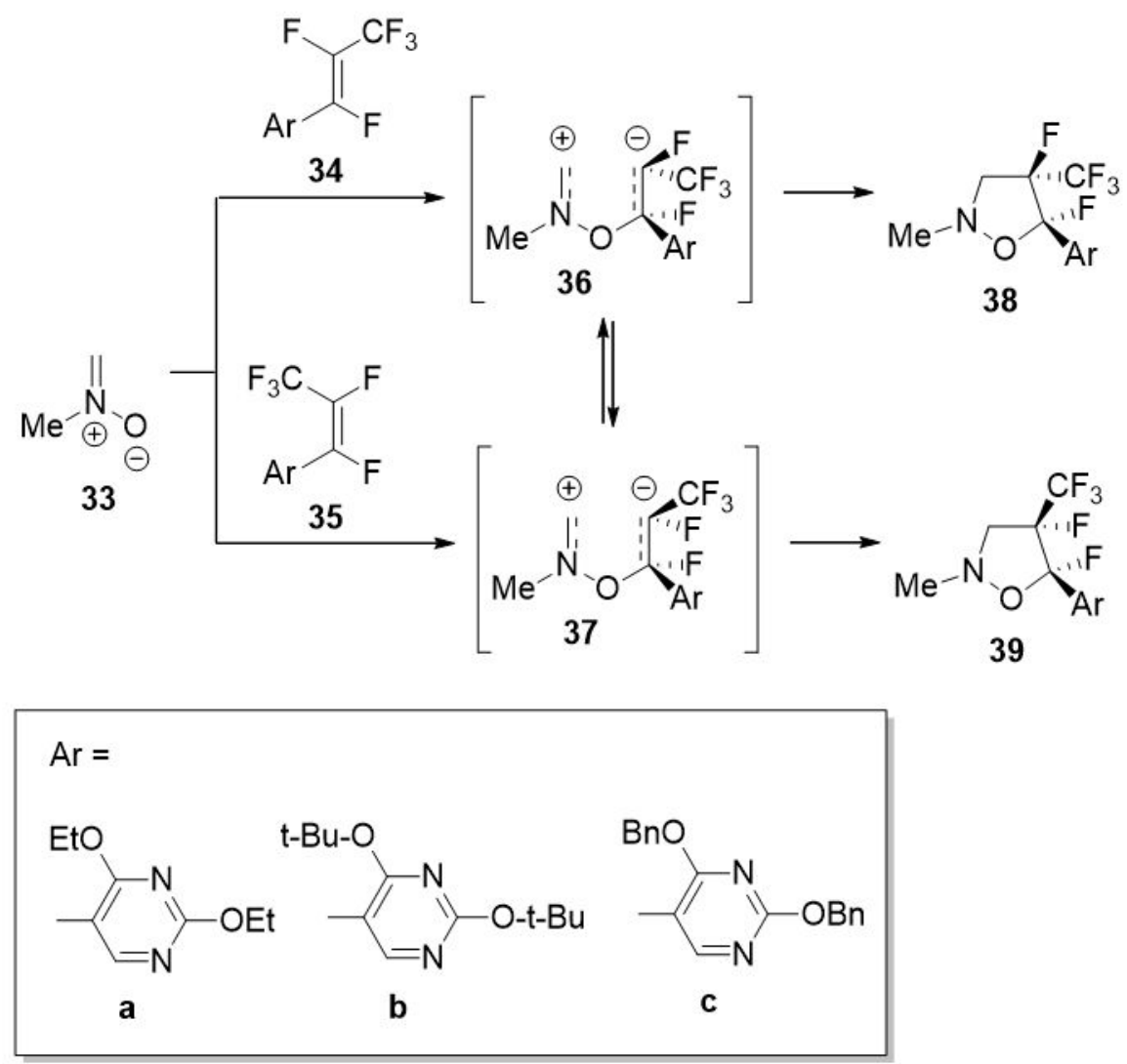

Scheme 9. Mechanism of 32CA of $N$-methylnitrone with (E)- and (Z)-1,1,1,2,3-pentafluoro-3-phenylethenes.

The [3+2] cycloadditions of the same alkenes with N-t-butyl nitrone are similar [33]. Other types of products that could indicate the stepwise 32CA mechanism were identified in the reaction medium of N-oxide 1-benzyl-4,5-diphenylimidazole 40 with 1,1-dicyano-2,2-di (trifluromethyl)ethene 41 [34] (Scheme 10). It turned out that, in an anhydrous environment, this reaction leads to the expected isoxazolidine 45. However, in the presence of water, zwitterion 42 traps the $\mathrm{H}_{2} \mathrm{O}$ molecule and then decomposes into simpler molecules 43 and 44.

In all three cases discussed above, the reaction mechanism is undoubtedly influenced by the fact that the $\mathrm{CF}_{3}$ groups tend to stabilize zwitterion structures [35].

The 32CAs of (Z)-C-(9-anthracene)- $N$-arylonitrones 46a-c with (E)-3,3,3-trichloro-1-nitroprop-1-ene 47 are realized in a completely regio- and stereo-selective manner, always leading to the corresponding 2-aryl-3-(9-anthracene)-4-nitro-5-trichloromethylisoxazolidine $49 \mathbf{a}-\mathbf{c}$ as the only cycloaddition product [16] (Scheme 11). It is significant that it is a relatively more spatially crowded product among those theoretically possible. This would mean that the approximation of the reaction centers takes place so asynchronously that, in the first reaction step, the bond between the carbon atom of the nitrone $\mathrm{CNO}$ fragment and the alpha carbon atom of the nitrovinyl fragment is not formed at all. This, in turn, implies the stepwise mechanism of the cycloaddition, the first step of which is the formation of the zwitterion. Due to the polar nature of additive interactions, this process is easy, and therefore it is definitely favored over other theoretically possible ways of transforming substrates. Comprehensive DFT calculations, performed in parallel with the experimental work, fully confirmed the above assumptions. 


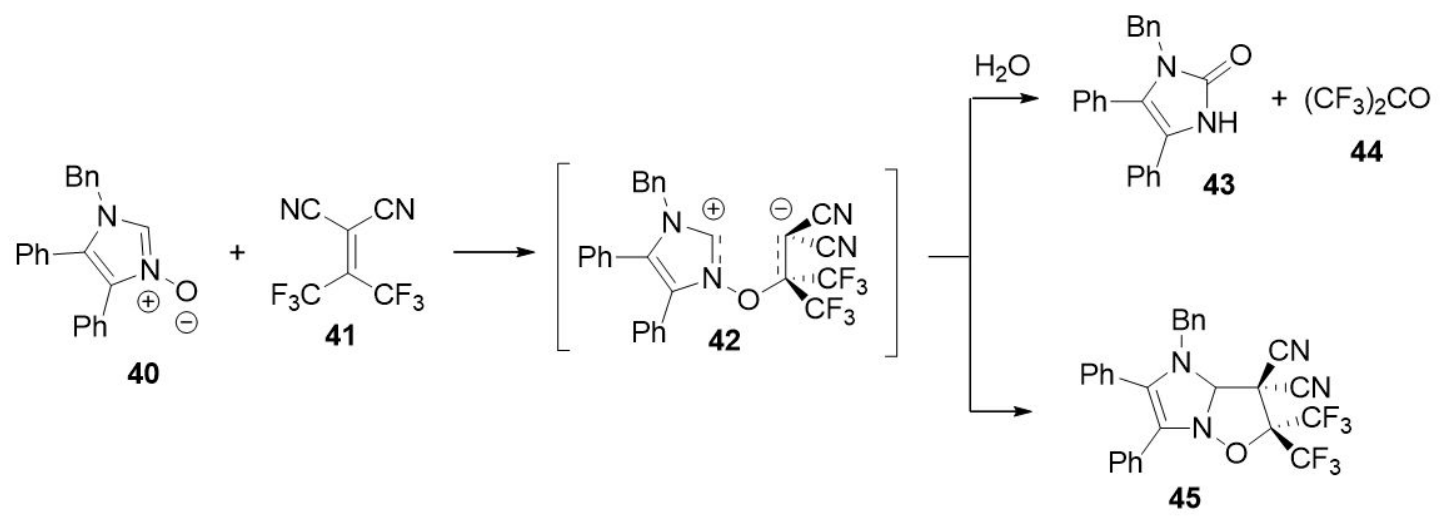

Scheme 10. Mechanism of 32CA of 1-benzyl-4,5-diphenylimidazole N-oxide with 1,1-dicyano-2,2-di(trifluromethyl)ethene.

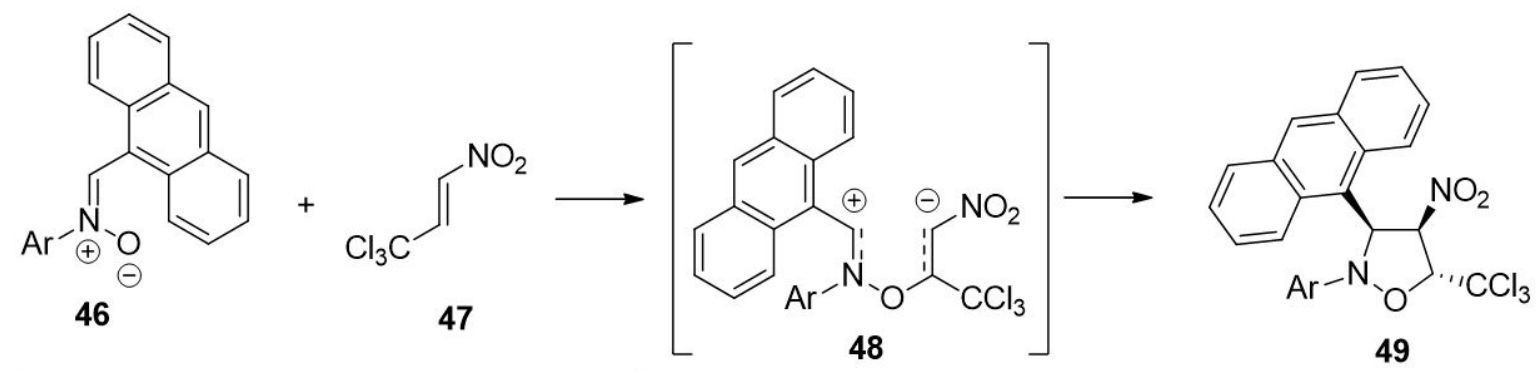<smiles>Cc1ccc(Cl)cc1</smiles>

Scheme 11. Mechanism of 32CA of (Z)-C-(9-anthracene)- $N$-arylonitrones with (E)-3,3,3-trichloro-1-nitroprop-1-ene.

Similarly, the view of a stepwise zwitterionic mechanism of a similar, completely regio- and stereo-selective 32CAinvolving (Z)-C-(3,4,5-trimethoxyphenyl)- $N$-methylnitrone 50 and (Z)-3,3,3-trichloro-1-bromo-1-nitroethene (51) has been documented [36,37] (Scheme 12).<smiles>COc1cc(C=[N+]([O-])[O-])cc(OC)c1OC</smiles>

50<smiles>CC(Cl)(Cl)C=C(Br)[N+](=O)OC(C)(C)C</smiles>

51<smiles>COc1cc(CN(C)OC(=O)C(=O)OCc2ccccc2)cc(OC)c1OC</smiles><smiles>COc1cc(C2C(Br)[C@H](C(Cl)(Cl)[N+](=O)[O-])ON2C)cc(OC)c1OC</smiles>

53

Scheme 12. Mechanism of 32CA of (Z)-C-(3,4,5-trimethoxyphenyl)- $N$-methylnitrone with (Z)-3,3,3-trichloro-1-1-bromo-1-nitroprop-1-ene.

The presence of a bromine atom, which additionally shields the $\alpha$-carbon atom of the nitrovinyl fragment, undoubtedly plays a key role in imposing the zwitterionic mechanism of this transformation. It is known that the 32CAreactions of the same nitrone with 2-substituted nitroethenes follow the polar and asynchronous, but one-step, mechanisms [38] (Scheme 13). 


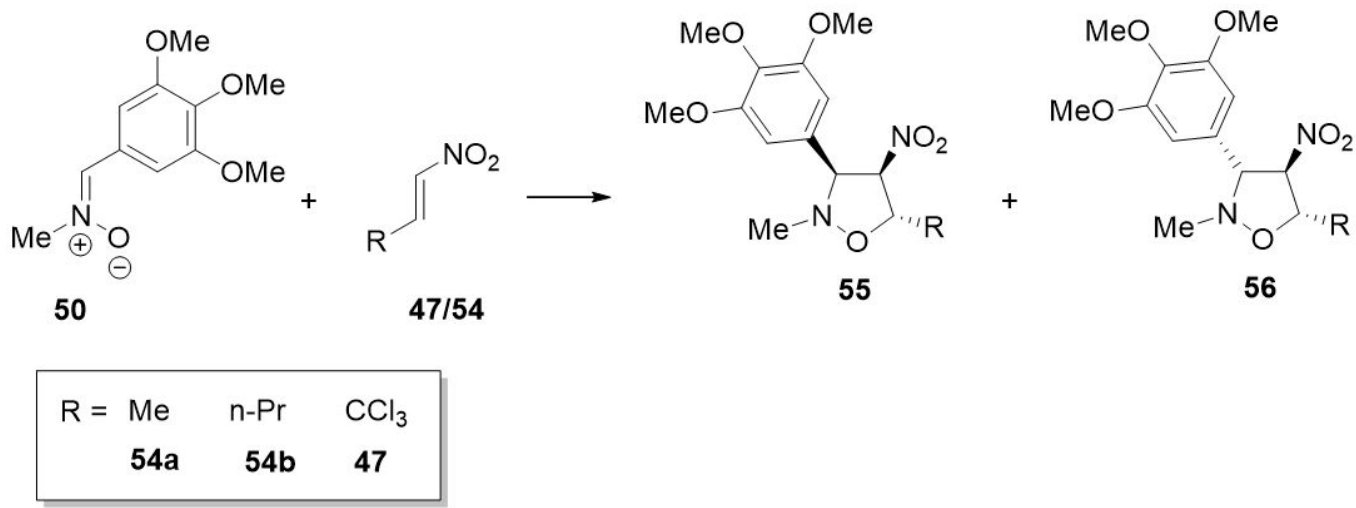

Scheme 13. Mechanism of 32CA of (Z)-C-(3,4,5-trimethoxyphenyl)-N-methylnitrone with (E)-2-R-1-nitroethenes.

Experimental and theoretical studies have shown that 32CA of (Z)-C,N-diphenylnitrone 21 to nitroethene $\mathbf{1 7}$ is carried out in accordance with the one-step mechanism [39]. However, in the course of a similar reaction involving the selenyl analog of nitrone 59, the formation of zwitterionic transition structures is possible [40] (Scheme 14). Similar studies were also carried out on a similar reaction with the sulphur analog of nitrone [41] but did not show the possibility of zwitterion formation.

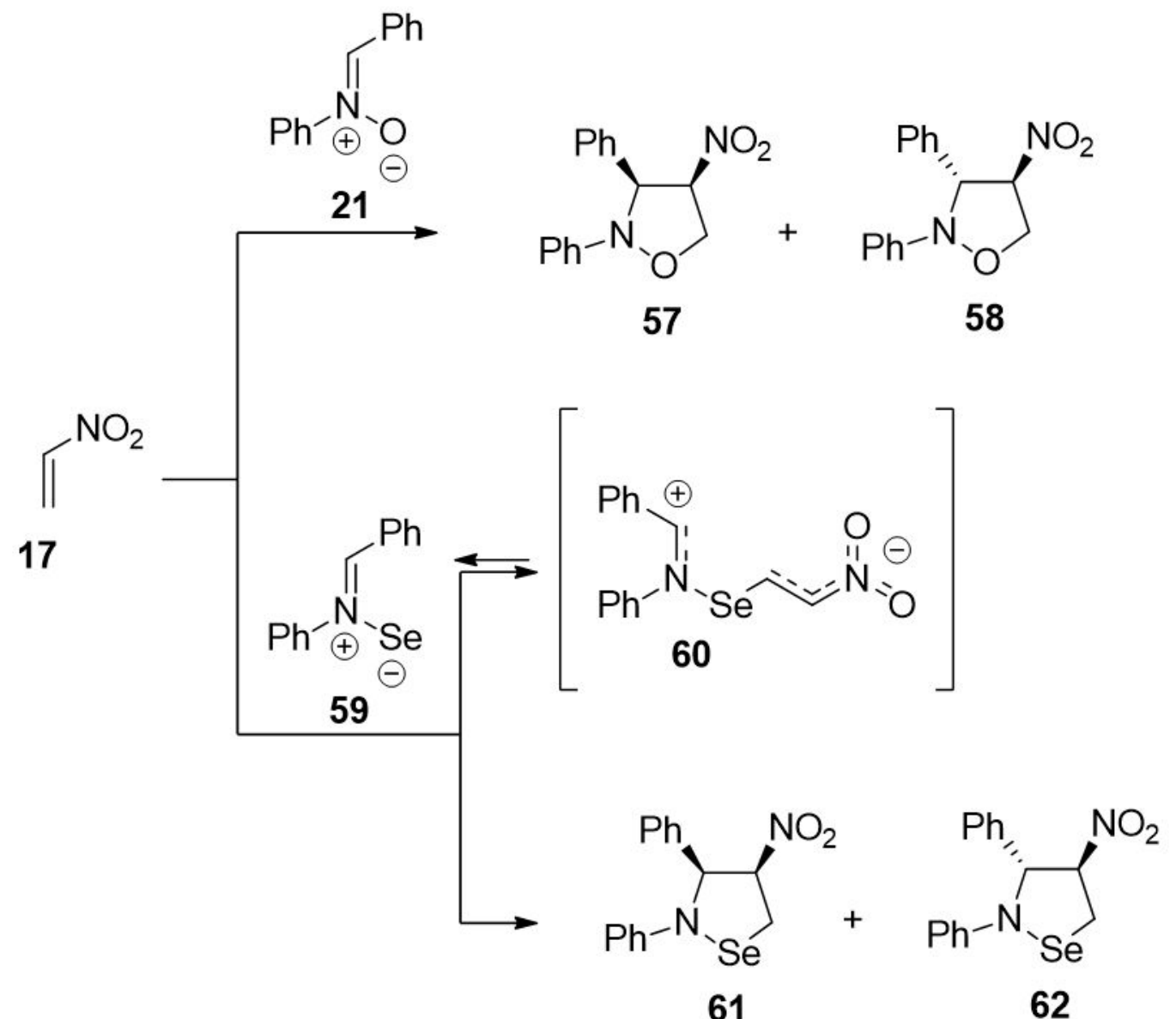

Scheme 14. Mechanism of 32CA of (Z)-C,N-diphenylnitrone and its seleno analogue with nitroethene.

The 32CA of (Z)-C,N-diarylnitrones 63a-d with 1-chloronitroethene 64 are completely regio-selective and lead to stereo-isomeric mixtures of 3,4-trans- and 3,4-cis-2,3-diaryl-4-chloro-4-nitroisoxazolidine (67a-d 
and 68a-d, respectively) [42] (Scheme 15). Comprehensive studies of the influence of the nature of the substituent and the polarity of the environment on the stereo-selectivity and kinetics of the reaction show that these reactions are carried out in accordance with a single-step mechanism. DFT theoretical research leads to a similar conclusion. Analogous studies suggest that, in the environment of dialkylimidazolium ionic liquids, the same cycloadditions should occur in accordance with the stepwise mechanism. This is a result of increasing the electrophilicity of nitroalkene through its complexation with dialkylimidazolium cations [BMIM].
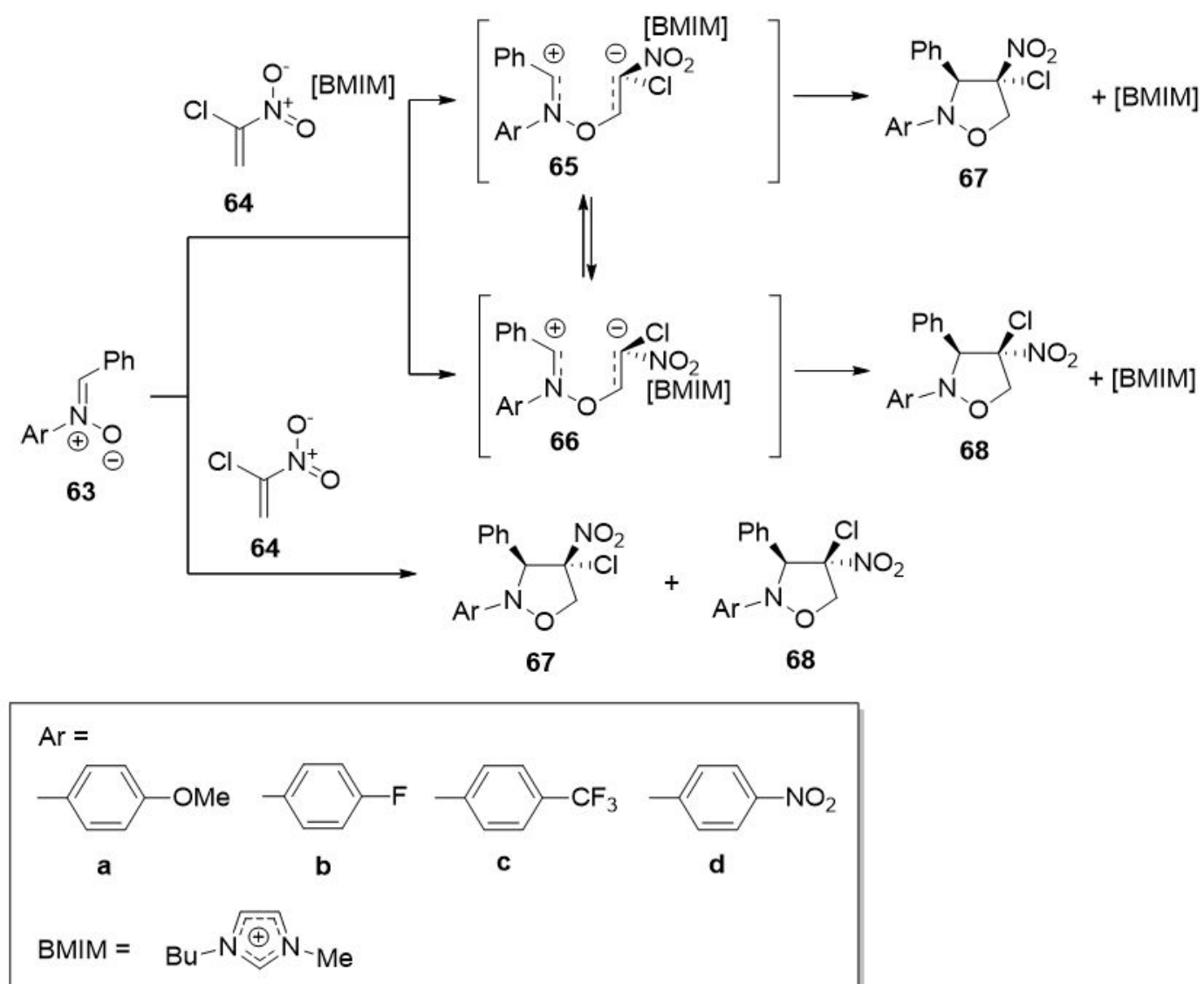

Scheme 15. Mechanism of 32CA of (Z)-C-phenyl-N-arylonitrones with 1-chloronitroethene under thermal conditions and in the presence of dialkylimidazolium cations of ionic liquids.

A similar effect of the presence of dialkylimidazolium cations in ionic liquids on the reaction mechanism was previously noted with respect to [4+2] cycloaddition [43].

The research conducted so far focused on 32CA of nitrone 21 with extremely electrophilic nitroalkene 1,1-dinitroethene 69 [44] (Scheme 16). These studies suggest that, in the gas phase, the analyzed reaction should follow a two-stage one-step mechanism, though through a strongly asynchronous transition state. The introduction of even a slightly polar solvent to the reaction environment forces the change of the mechanism to stepwise.

Much less often than nitrones, esters of nitronic acids (nitronates)-structurally related to nitrones-are tested as components of [3+2] cycloadditions. Also in this group of TACs are examples of reactions in the course of which the formation of zwitterionic intermediates is possible. For example, the push-pull reaction of nitronate $\mathbf{7 2}$ with nitroethene $\mathbf{1 7}$ is performed in a fully regio-selective manner yielding 2-methoxy-3,3-dicarbomethoxy-5-nitroisoxazolidine as the only cycloaddition product [45] (Scheme 17). The exploration of reaction pathways using DFT methods showed [46] that the interactions of additions can lead to the formation of unstable zwitterionic intermediates. 


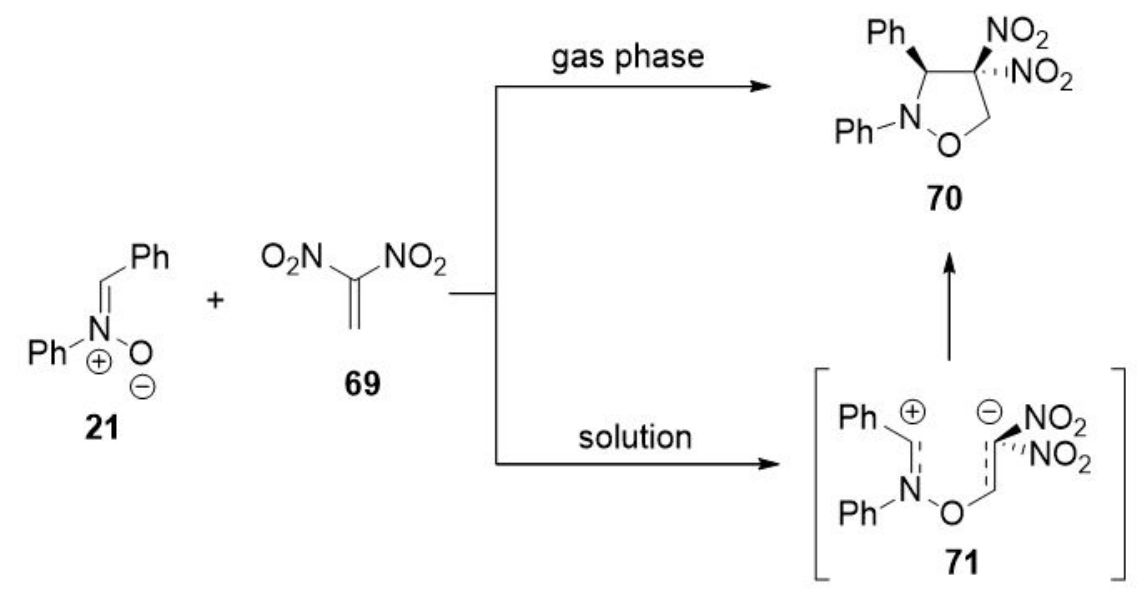

Scheme 16. Mechanism of 32CA of (Z)-C,N-diphenylnitrone with 1,1-dinitroethene in the gas phase and in solution.

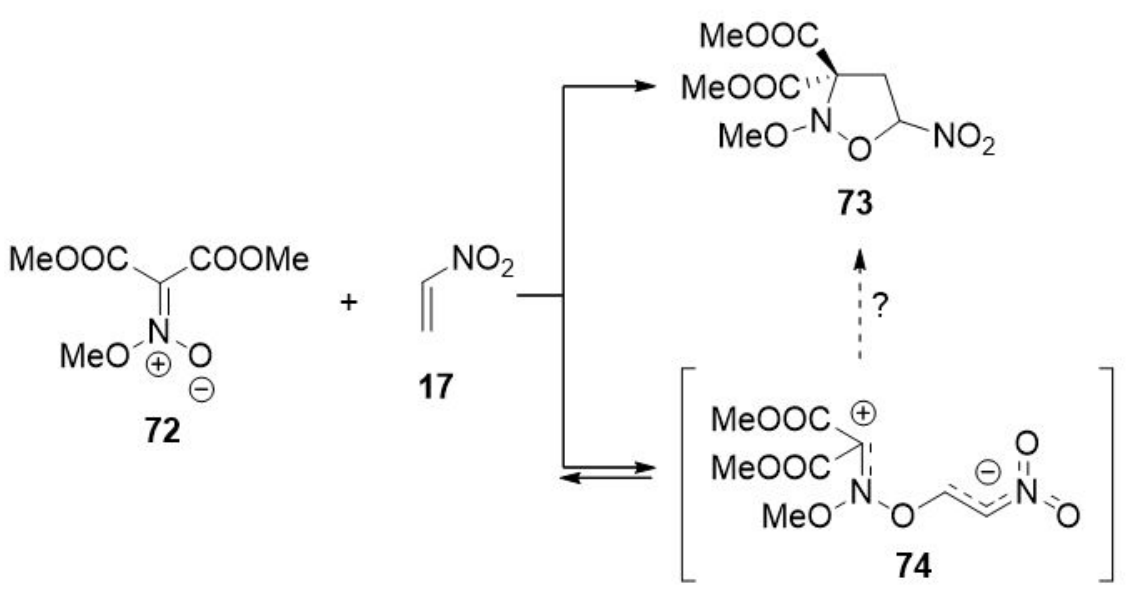

Scheme 17. Mechanism of 32CA of N-methoxy-C,C-dicarbomethoxy imine N-oxide with nitroethene.

Aromatic amine oxides are not formally recognized as nitrones, but their $>\mathrm{C}=\mathrm{N}(\mathrm{O})$ fragment with activated alkenes can react according to the 32CA scheme [47,48]. In this case, the zwitterionic intermediate mechanism (Scheme 18) has been postulated from reactions involving pyridine N-oxide and a series of isocyanates. However, this postulate was based solely on the semi-empirical data of PM3 calculations, and as we know [49], this type of approach suggests a geometry of the transition states that differs significantly from the real ones. Therefore, the proposed mechanism should be approached with caution.

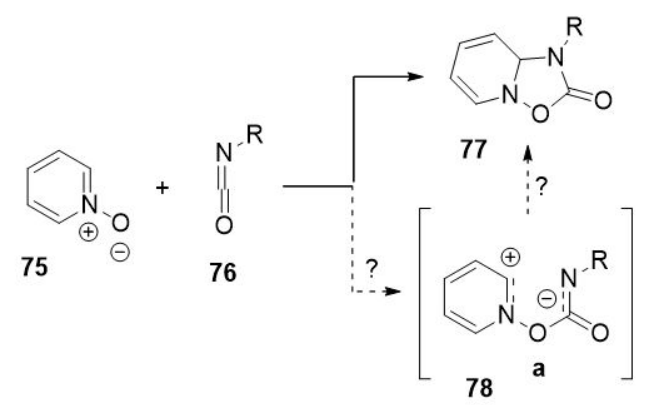

Scheme 18. Mechanism of 32CAof pyridine N-oxide with isocyanates. 


\subsection{Azomethine Ylides}

Reactions of $\pi$-deficient cyclic ylides $79 a-f$ with dimethylaminopropyne 80 always yield one product (Scheme 19). Comprehensive kinetic studies have shown that these reactions are much more sensitive to environmental polarity than typical 32CA involving simple components [50]. For example, the model reaction rate constant in low polar toluene is 70 times lower than that in clearly polar acetonitrile. This allows the assumption that the reaction is polar in nature and that the presence of zwitterionic intermediate cannot be ruled out. However, recent MEDT studies [51] do not confirm this hypothesis. The transition states, optimized by DFT calculations, are indeed of an asynchronous nature, but not so much that it is possible to enforce the stepwise mechanism.
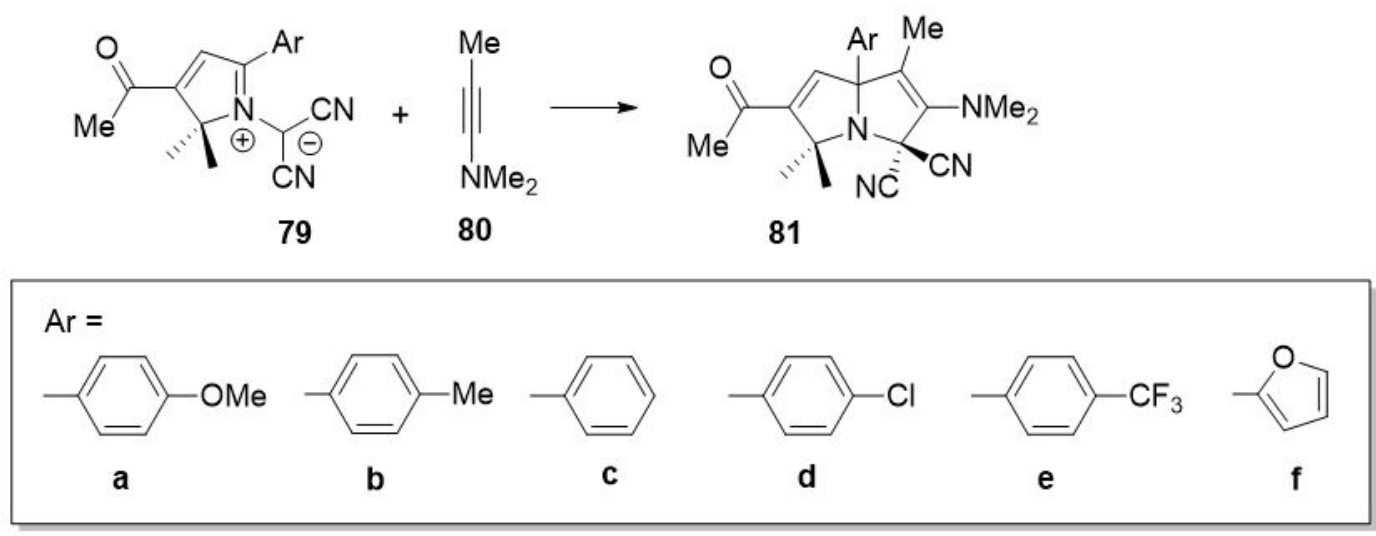

Scheme 19. Mechanism of 32CA of $\pi$-deficient cyclic ylides with dimethylaminopropyne.

The stereo-selectivity of 32CA of 1,3-diphenyl- $N$-methyl-azomethine ylide 82 with 1,2-dicyanofumarate dimethyl 6 and 1,2-dicyanomaleate dimethyl 7 is, qualitatively, similar to the analogous reaction with 2,2,4,4-tetramethyl-3-thiocyclobutanone S-methylide $5 \mathbf{b}$ [17] with the same alkenes (Scheme 20). In particular, in both cases, products are formed with a relative configuration of nitrile groups identical to that observed in alkene, and the reverse [52]. The loss of the stereo-configuration contributed from the starting material, therefore, indicates that rotation around the MeOOC $(\mathrm{CN})-\mathrm{C}-\mathrm{C}-(\mathrm{CN}) \mathrm{COOMe}$ bond must have occurred in the course of the reaction. This, in turn, implies the necessity of the appearance of acyclic intermediates in the environment of reactions. In this case, simulations of the reactionary paths made on the basis of complex quantum-chemical calculations fully confirm the thesis, based on the results of experimental work.

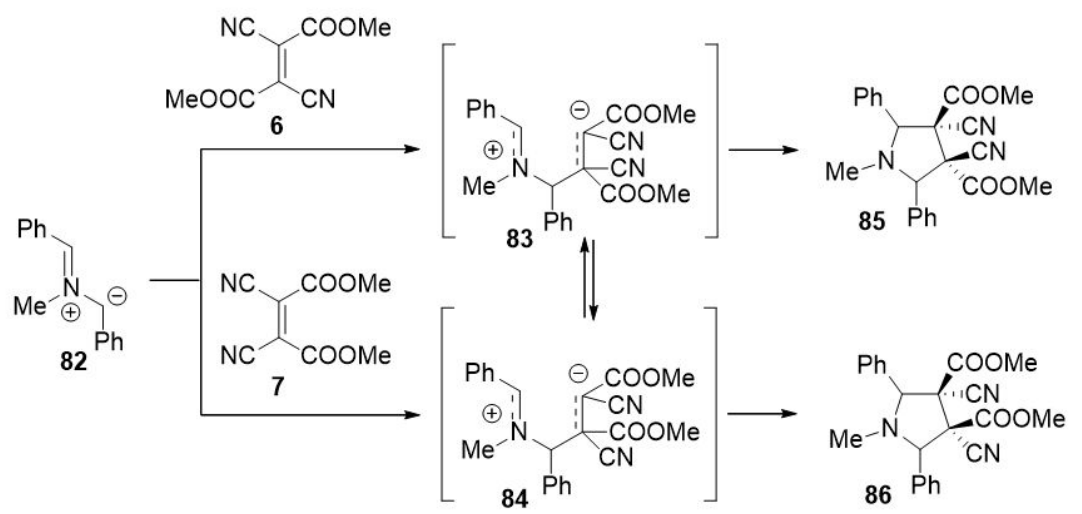

Scheme 20. Mechanism of 32CA of 1,3-diphenyl-N-methyl-azomethine ylide with 1,2-dicyanofumarate and dimethyl 1,2-dicyanomaleate. 
According to the zwitterionic mechanism, there may be a reaction between N-methylazomethine ylide and (E)-2-aryl-1-cyano-1-nitroethenes [53] (Scheme 21). This is carried out under mild conditions and leads to the corresponding 1-methyl-3-cyano-3-nitro-4-arylpyrrolidines in high yields. The authors of [53] analyzed the nature of the intermolecular interactions in the elementary reaction, and found that they were clearly polar. The zwitterionic mechanism is supported by the fact that other nucleophilic TACs react with (E)-2-aryl-1-cyano-1-nitroethenes to form zwitterionic structures [54]. Unfortunately, the research material collected so far does not provide grounds for an unequivocal conclusion on this subject.

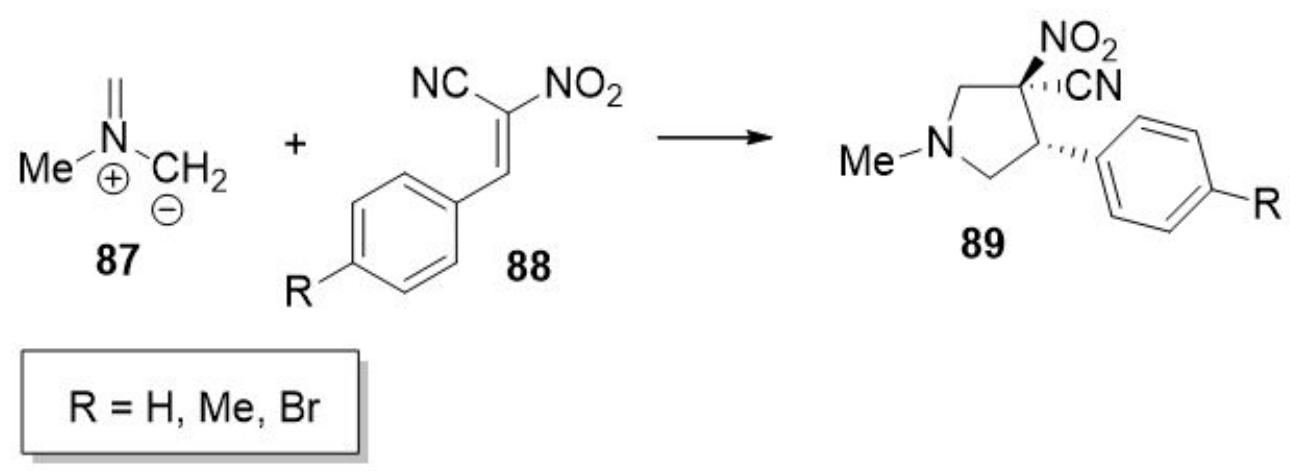

Scheme 21. Mechanism of 32CA of N-methyl-azomethine ylide with (E)-2-aryl-1-cyano-1-nitroethenes.

\subsection{Nitrile N-Oxides and Azides}

The stepwise mechanism of 32CA was postulated in the 1970s in relation to the reaction of 3,5-dichloro-2,4,6-trimethylbenzonitrile N-oxide with a series of arylacetylenes (Scheme 22). In these reactions, in addition to the expected isoxazoles 92, acyclic adducts 95 are simultaneously formed, which may be conversion products of the originally formed zwitterions [55]. However, a comprehensive study of the reaction kinetics performed somewhat later [56] ruled out the possibility that the zwitterionic intermediate could exist in the additive conversion pathway to isoxazole. It is most likely that the ionic character is only a completely independent and competitive reaction leading to 95 .

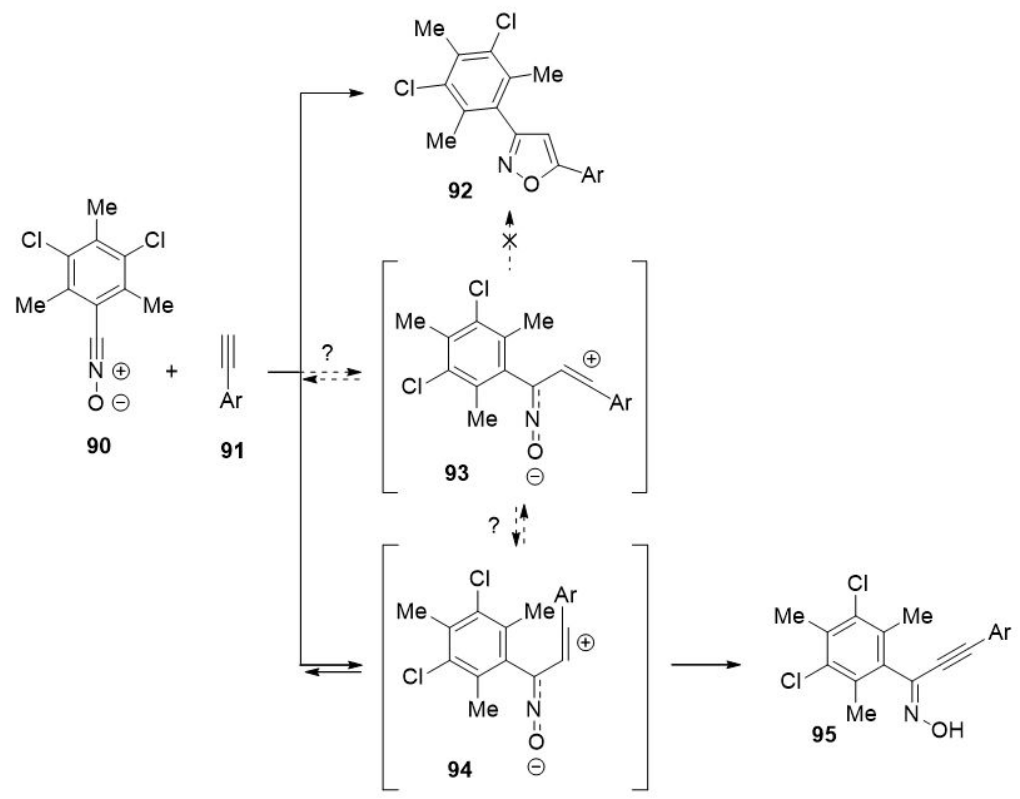

Scheme 22. Mechanism of 32CA of 3,5-dichloro-2,4,6-trimethylbenzonitrile N-oxide with arylacetylenes. 
It is likely that the reaction mechanism of benzonitrile N-oxide 96 with 1,1,2,2,3,3-hexamethyl-4,5-dimethylenecyclopentane 22a is similar to that described above [57] (Scheme 23). In this reaction, besides the expected spirocyclic isoxazoline $\mathbf{9 7}$, oxime 99 is also formed.

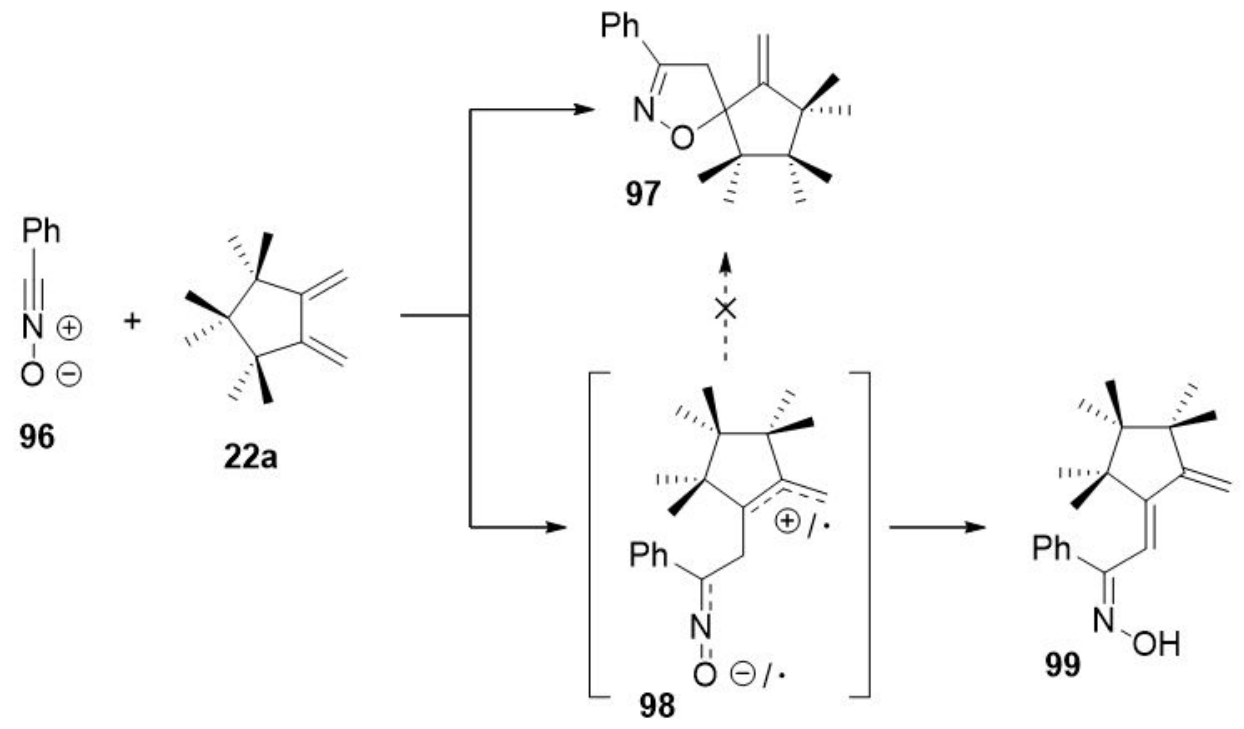

Scheme 23. Mechanism of 32CA of benzonitrile N-oxide with 1,1,2,2,3,3-hexamethyl-4,5-dimethylenecyclopentane.

The presence of zwitterionic intermediates is more likely in the reaction of aromatic nitrile $\mathrm{N}$-oxides 96 with nitroacetylene 100 (Scheme 24). DFT studies of the model reaction with the participation of benzonitrile N-oxide showed [58] that the interactions of additions can, in this case, lead to the formation of an extended zwitterion. A similar reaction mechanism is suggested by analogous theoretical studies for the reaction of phenyl azide 101 with the same nitroacetylene 100 (Scheme 24).

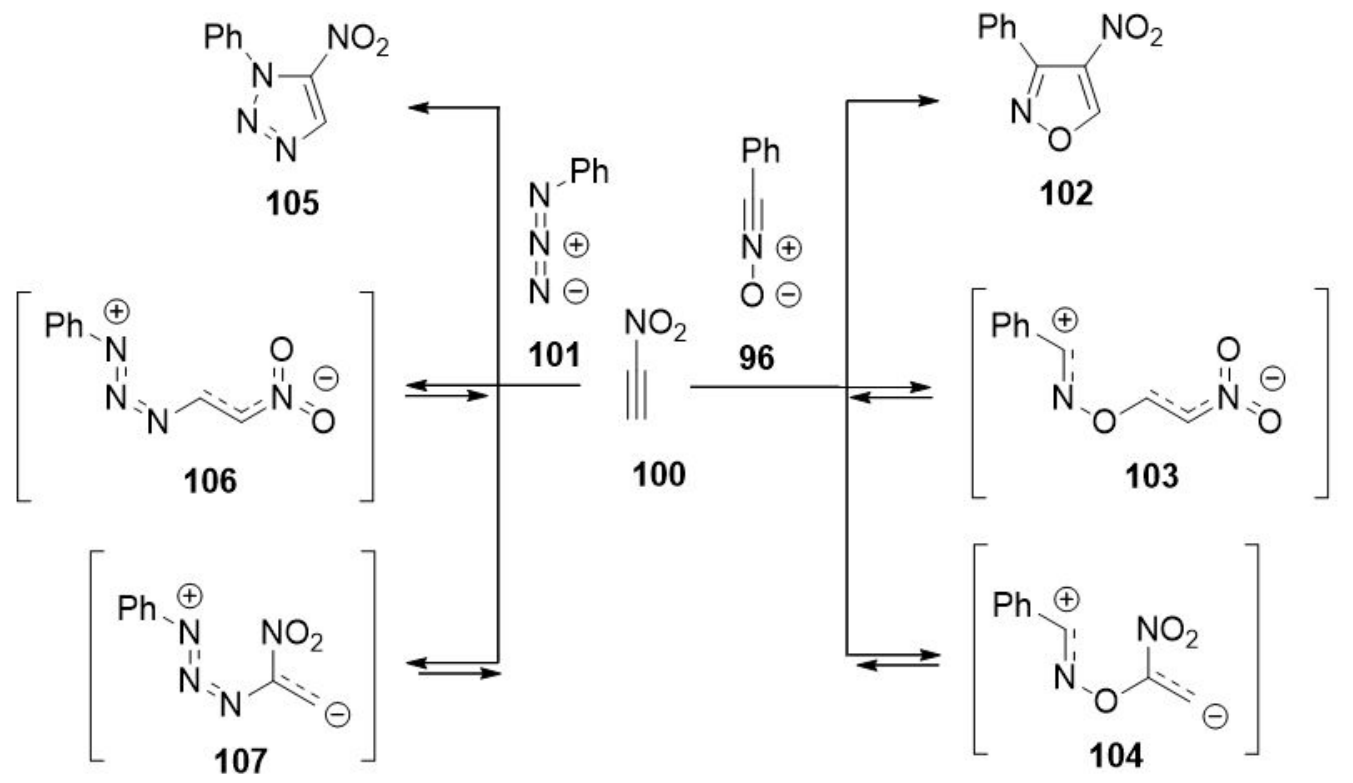

Scheme 24. Mechanism of hypothetical 32CA of benzonitrile N-oxide and phenyl azide with nitroacetylene.

The mechanistic studies of the 32CA of acetonitrile N-oxide 108 with tetraaminoethylene 109 [59] (Scheme 25) are also completely theoretical. DFT calculations allow for the formation of various 
zwitterionic forms in the course of the reaction, one of which, with a "cyclic" conformation, may be further converted to 3-methyl-4,4,5,5-tetraaminoisoxazoline 112. Similar conclusions are drawn by analogous studies with regard to 32CA of trifluoroacetonitrile $\mathrm{N}$-oxide with vinylamine [60].

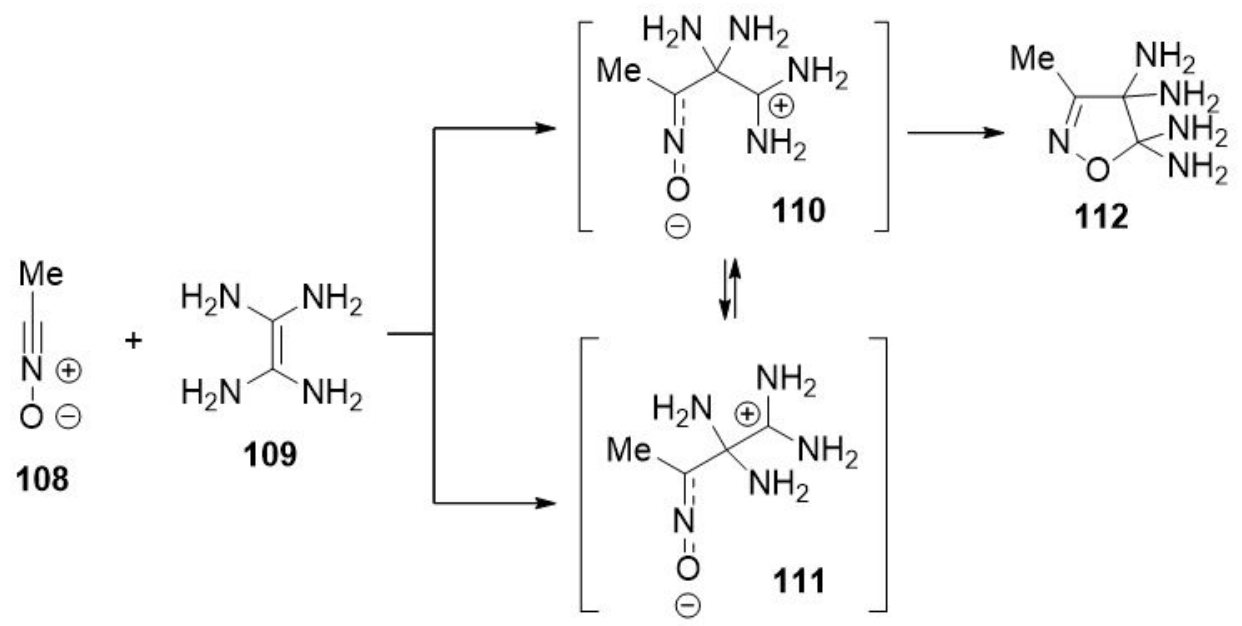

Scheme 25. Mechanism of hypothetical 32CA of acetonitrile N-oxide with tetraaminoethene.

Absolute evidence of zwitterion on the 32CA pathway was obtained in the case of $\pi$-deficient 113a-e azides reactions with 5-alkylidenedihydrotetrazole $\mathbf{1 1 4}$ [61,62] (Scheme 26). This zwitterion was able to be isolated in a stable form at low temperatures and identified using the X-ray technique. Its cyclization takes place only at an elevated temperature, which at the same time causes a spontaneous decomposition of the resulting cycloadduct according to the retro-32CA scheme leading to dimethyldiazomethane $\mathbf{1 1 8}$ and imine 117a-e.

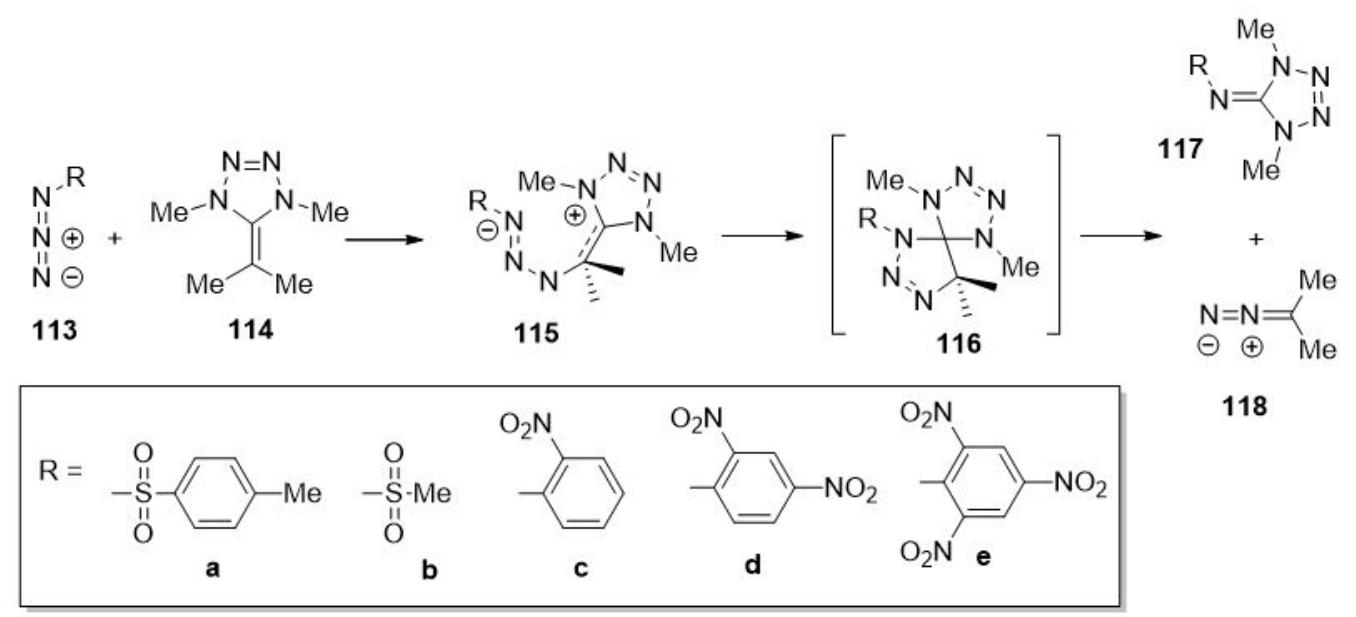

Scheme 26. Mechanism of 32CA of $\pi$-deficient azides with 5-alkylidenedihydrotetrazole.

\subsection{Diazocompounds}

Stepwise, the zwitterionic mechanism of 32CA of diaryldiazomethanes 119a-c from hexafluoroacetone 120 was postulated in the 1970s [63] (Scheme 27). This hypothesis was based on the clearly nucleophilic nature of TACs and the $\pi$-deficit nature of hexafluoroacetone 120 . Such a mechanism could be additionally favored by the stabilization of zwitterionic structures by $\mathrm{CF}_{3}$ groups [35]. However, recently conducted comprehensive DFT studies [64] have shown that the analyzed cycloadditions are carried out in accordance with the polar, but one-step mechanism. 


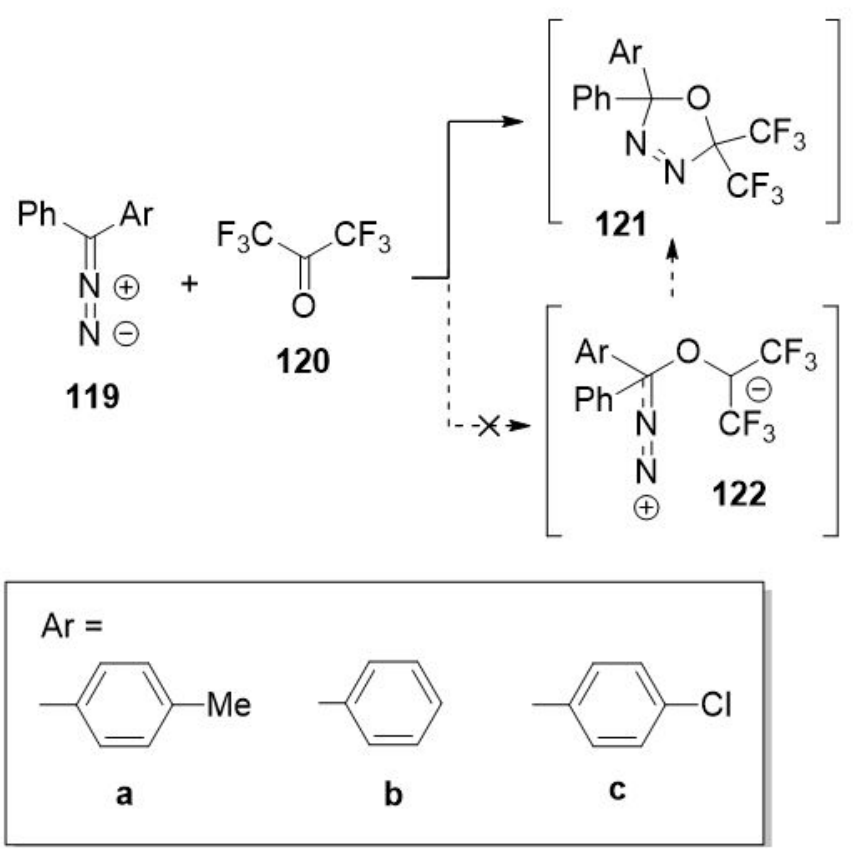

Scheme 27. Mechanism of 32CA of diaryldiazomethanes with hexafluoroacetone.

In the reactions of diazafluorene 123 with $(E)$-2-aryl-1-cyano-1-nitroethenes 88a, 124a-c instead of the expected nitropirazolines 127, azines 126 [54] are formed, the structure of which has been confirmed unambiguously by X-ray analysis (Scheme 28). This led to the assumption that in the first step of the reaction, zwitterionic intermediate $\mathbf{1 2 5}$ is formed, which is then converted only in the next step. Comprehensive DFT studies carried out in parallel have fully confirmed this assumption. It is significant that (E)-3,3,3-trichloro-1-nitroprop-1-en 47, despite its global electrophilicity being almost identical to 124, reacts with diazafluorene to give pyrazoline 128. Theoretical studies have shown that this transformation takes place without the intermediate (Scheme 28).

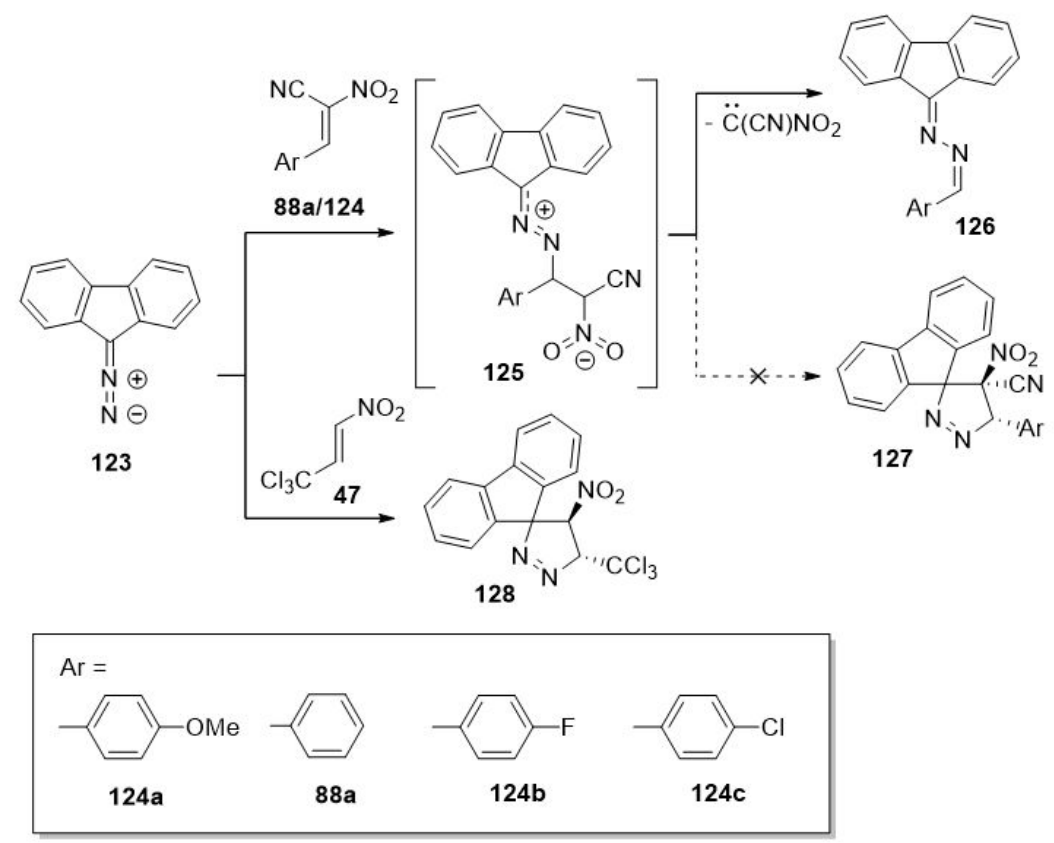

Scheme 28. Mechanism of 32CA of diazafluorene with EWG -functionalized nitroethenes. 
As shown by comprehensive experimental and quantum chemical studies [65], the stage of the attack of the nucleophilic nitrogen atom on the strongly $\pi$-deficit bond $>C=C<$ with the formation of zwitterion initiates not only the reaction of diazofluorene 123 with E-2-aryl-1-cyano-1-nitroethenes 88a, 124a-c, but also the reaction of the same TAC with dimethyl 1,2-dicyanofumarate 6 and dimethyl 1,2-dicyanomaleate 7 (Scheme 29). The intermediates thus formed may be isomerized, as a result of which its Z-isomer appears in the reaction medium with E-2,3-dicyanobutenedioate, and its E-isomer appears in the reaction medium with Z-2,3-dicyanobutenedioate. As a consequence, adducts are formed each time, side by side with the relative configuration of the $\mathrm{CN}$ groups identical to the starting alkene and inverse. These adducts are not stable under the reaction conditions and by elimination of $\mathrm{N}_{2}$ molecules they are stereo-selectively converted to the corresponding cyclopropanes. The molecular mechanism of the reaction of diphenyldiazomethane $\mathbf{1 1 9 b}$ and other diazo compounds with the same alkenes is similar [65].
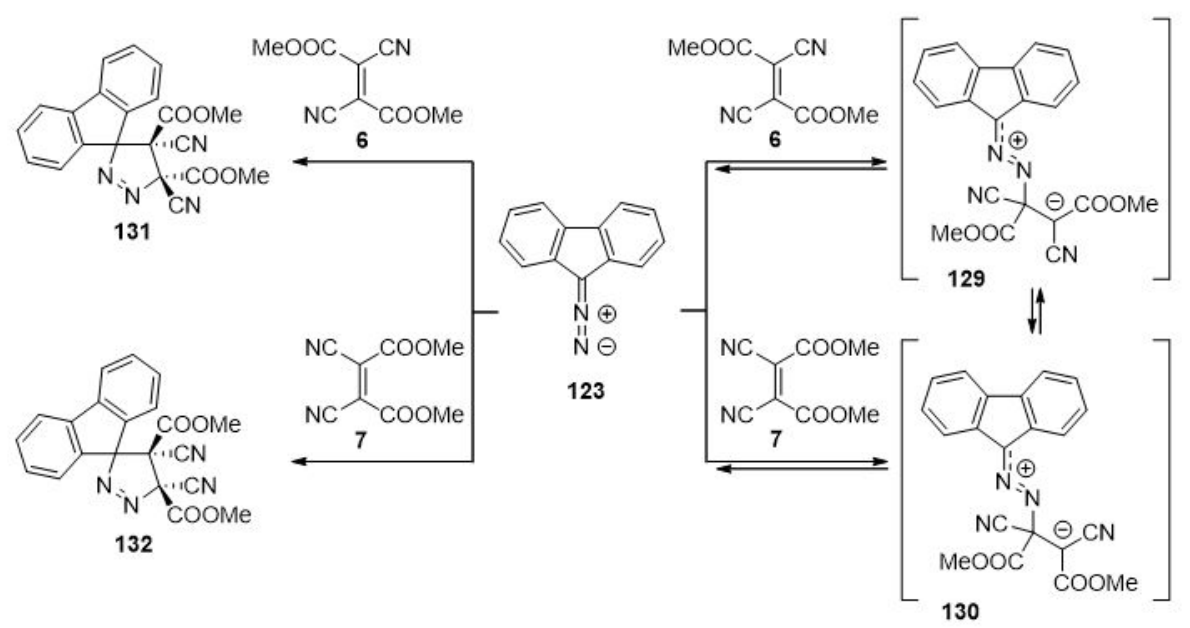

Scheme 29. Mechanism of 32CA of diazafluorene with dimethyl 1,2-dicyanofumarate and dimethyl 1,2-dicyanomaleate.

However, the expected zwitterionic intermediates could not be detected in any way in the case of 32CA of diphenyldiazomethane 119b with di(het)arylthioketones 133a-c [66] (Scheme 30). These reactions follow a one-step mechanism, producing 2,2,5,5-tetraaryl-1,3,4-thiadiazolines 137a-c undergoing spontaneous $\mathrm{N}_{2}$ elimination $[67,68]$. This elimination does not lead directly to the corresponding tiranes, but to ylide 136, which cyclizes only in the next step [66].

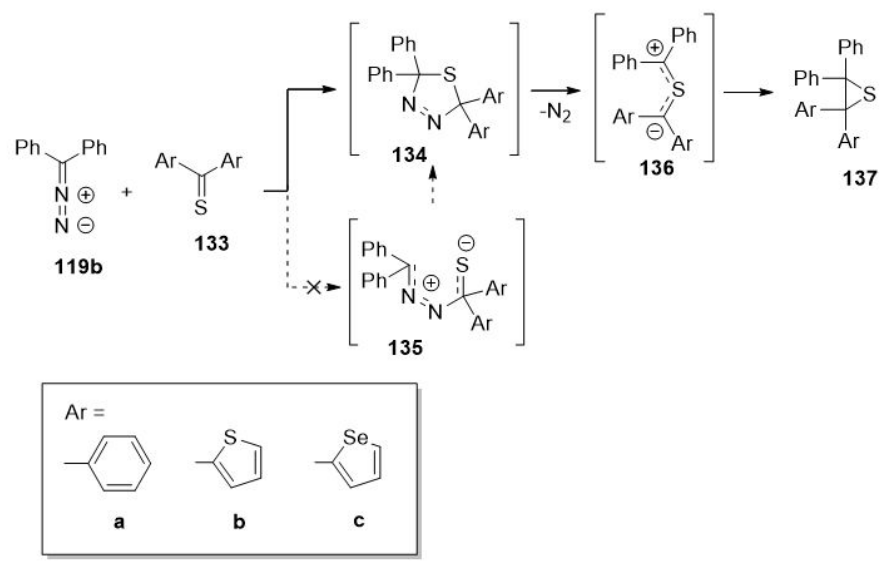

Scheme 30. Mechanism of 32CA of diphenyldiazomethane with diarylthioketones. 


\section{Conclusions}

Research on the mechanistic aspects of the 32CA reaction has been ongoing for several dozen years. It has long been postulated that, in addition to the commonly recognized one-step mechanism, such reactions can also take place in accordance with multi-step mechanisms, with the participation of zwitterion intermediates. However, the research material supporting these postulates is of varying value. Most often, it is the nature of the products isolated in the reaction mass. Such evidence may or may not be decisive in determining the response mechanism. There is work in which, apart from the purely synthetic part, the authors have more valuably attempted to perform kinetic studies or quantum chemical calculations. Finally, there is a group of work that is interesting from the cognitive point of view, but concerns reactions that have not been verified so far, or even reactions involving strictly hypothetical components. However, while even 30 years ago, stepwise cycloadditions were referred to as incidental cases, as exceptions to the rule, stepwise zwitterionic cycloadditions should today be classified as a real group of reactions that can be realized in diagnosable realities. They are, for example, a large difference in the polarity of additions, a large differentiation in the degree of shielding of unsaturated systems, the polar reaction environment, and the presence of structural fragments stabilizing zwitterionic structures. The issues covered in this review are currently the subject of intense research by many teams around the world.

Author Contributions: R.J. Headed the subject, reviewed the literature, wrote the manuscript; E.D. Reviewed the literature, wrote the manuscript. All authors have read and agreed to the published version of the manuscript.

Funding: No financial support.

Conflicts of Interest: There are no conflicts to declare.

\section{References}

1. Buchner, E. Einwirkung von Diazoessigäther auf die Aether ungesättigter Säuren. Chem. Ber. 1888, 21, 2637-2647. [CrossRef]

2. Huisgen, R. Kinetics and Mechanism of 1,3-Dipolar Cycloadditions. Angew. Chem. Int. Ed. 1963, 2, 633-696. [CrossRef]

3. Huisgen, R. 1,3-Dipolar cycloadditions. 76. Concerted nature of 1,3-dipolar cycloadditions and the question of diradical intermediates. J. Org. Chem. 1976, 41, 403-419. [CrossRef]

4. Hoffman, R.V. Organic Chemistry, 2nd ed.; Wiley: New Jersey, NJ, USA, 2004; pp. 312-324.

5. Carey, F.A.; Sundberg, R.J. Advanced Organic Chemistry. Part A: Structure and Mechanisms, 5th ed.; Springer: New York, NY, USA, 2007; pp. 834-892.

6. Huisgen, R. Cycloadditions-Definition, Classification, and Characterization. Angew. Chem. Int. Ed. 1968, 7, 321-328. [CrossRef]

7. Huisgen, R. Cycloaddition mechanism and the solvent dependence of rate. Pure Appl. Chem. 1980, 52, 2283-2302. [CrossRef]

8. Firestone, R.A. Mechanism of 1,3-dipolar cycloadditions. J. Org. Chem. 1968, 33, 2285-2290. [CrossRef]

9. Firestone, R.A. Applications of the Linnett electronic theory to organic chemistry. Part III. Linnett structures for 1,3-dipoles and for the diradical intermediates in 1,3-dipolar cycloadditions. J. Chem. Soc. A. 1970, 1570-1575. [CrossRef]

10. Firestone, R.A. Application of the Linnett electronic theory to organic chemistry. V. Orientation in 1,3-dipolar cycloadditions according to the diradical mechanism. Partial formal charges in the Linnett structures of the diradical intermediate. J. Org. Chem. 1972, 37, 2181-2191. [CrossRef]

11. Huisgen, R.; Mloston, G.; Langhals, E. The first two-step 1,3-dipolar cycloadditions: Interception of intermediate. J. Org. Chem. 1986, 51, 4085-4087. [CrossRef]

12. Huisgen, R.; Mloston, G.; Langhals, E. The first two-step 1,3-dipolar cycloadditions: Non-stereospecificity. J. Am. Chem. Soc. 1986, 108, 6401-6402. [CrossRef]

13. Domingo, L.R. Molecular Electron Density Theory: A Modern View of Reactivity in Organic Chemistry. Molecules 2016, 21, 1319. [CrossRef] [PubMed] 
14. Ríos-Gutiérrez, M.; Domingo, L.R. Unravelling the Mysteries of the 32CAReactions. Eur. J. Org. Chem. 2019, 2019, 267-282. [CrossRef]

15. Domingo, L.R.; Sáez, J.A. Understanding the mechanism of polar Diels-Alder reactions. Org. Biomol. Chem. 2009, 7, 3576-3583. [CrossRef]

16. Fialkov, Y.Y. Rastvoritel' kak Sredstvo Upravlenia Khimicheskim Processom; Khimya: Saint Petersburg, Russia, 1990; pp. 100-220.

17. Schwetlick, K. Kinetische Metoden zur Untersuchung von Reaktionsmechanismen; VEB Deutscher Verlag der Wissenschaften: Berlin, Germany, 1971; pp. 10-78.

18. Lan, Y.; Houk, K.N. Mechanism and Stereoselectivity of the Stepwise 1,3-Dipolar Cycloadditions between a Thiocarbonyl Ylide and Electron-Deficient Dipolarophiles: A Computational Investigation. J. Am. Chem. Soc. 2010, 132, 17921-17927. [CrossRef]

19. Domingo, L.R.; Picher, M.T. A DFT study of the Huisgen 1,3-dipolar cycloaddition between hindered thiocarbonyl ylides and tetracyanoethylene. Tetrahedron 2004, 60, 5053-5058. [CrossRef]

20. Huisgen, R.; Giera, H.; Polborn, K. 2,2,6,6-Tetramethylcyclohexanethione S-methylide, a highly hindered thiocarbonyl ylide: Two-step cycloadditions. Tetrahedron 2005, 61, 6143-6153. [CrossRef]

21. Huisgen, R.; Mloston, G.; Giera, H.; Langhals, E. Cycloadditions of two thiocarbonyl ylides with $\alpha, \beta$-unsaturated esters and nitriles: Steric course and mechanism. Tetrahedron 2002, 58, 507-519. [CrossRef]

22. Mloston, G.; Huisgen, R.; Giera, H. Reactions of a sterically hindered tetrasubstituted thiocarbonyl ylide with acceptor-substituted ethylenes; regioselectivity and stereochemistry. Tetrahedron 2002, 58, 4185-4193. [CrossRef]

23. Huisgen, R.; Mloston, G.; Langhals, E.; Oshima, T. 1,3-dipolar cycloadditions, part 126. Reactions of sterically hindered 'thiocarbonyl ylides' with 1,2-bis(trifluoromethyl)ethene-1,2-dicarbonitrile: Isolation of a cyclic seven-membered ketene imine. Helvetica Chimica Acta 2002, 85, 2668-2685. [CrossRef]

24. Huisgen, R.; Mloston, G.; Langhals, E. Cycloadditions of 'thiocarbonyl ylides' with tetracyanoethylene (=ethenetetracarbonitrile): Interception of intermediates. Helv. Chim. Acta 2001, 84, 1805-1820. [CrossRef]

25. Mloston, G.; Langhals, E.; Huisgen, R. 1,3-cycloadditions of aliphatic thione S-methylides to dimethyl 2,3-dicyanofumarate and 2,3-dicyanomaleate; a test case for steric course and mechanism. Tetrahedron Lett. 1989, 30, 5373-5376. [CrossRef]

26. Huisgen, R.; Penelle, J.; Mloston, G.; Buyle Padias, A.; Hall, H.K., Jr. Can polymerization trap intermediates in 1,3-dipolar cycloadditions? J. Am. Chem. Soc. 1992, 114, 266-274. [CrossRef]

27. Jasiński, R. In the searching for zwitterionic intermediates on reaction paths of 32CAreactions between 2,2,4,4-tetramethyl-3-thiocyclobutanone S-methylide and polymerizable olefins. RSC Adv. 2015, 5, 101045-101048. [CrossRef]

28. Kącka-Zych, A.; Jasiński, R. A DFT study on the molecular mechanism of the conjugated nitroalkenes polymerization process initiated by selected unsaturated nucleophiles. Theor. Chem. Acc. 2020, 139, 119. [CrossRef]

29. Baran, J.; Mayr, H. First [4+3]-cycloaddition of a 1,3-dipole with a 1,3-diene. J. Am. Chem. Soc. 1987, 109, 6519-6521. [CrossRef]

30. Baran, J.; Mayr, H. Competing [2+3] and [4+3] cycloadditions of C,N-diphenylnitrone with 1,3-dienes. Evidence for thermally nonequilibrated intermediates. J. Org. Chem. 1989, 54, 5774-5783. [CrossRef]

31. Yin, Z.; He, Y.; Chiu, P. Application of $(4+3)$ cycloaddition strategies in the synthesis of natural products. Chem. Soc. Rev. 2018, 47, 8881-8924. [CrossRef]

32. Jasiński, R. A new insight on the molecular mechanism of the reaction between (Z)-C,N-diphenylnitrone and 1,2-bismethylene-3,3,4,4,5,5-hexamethylcyclopentane. J. Mol. Graph. Model. 2020, 94, 107461. [CrossRef]

33. Wójtowicz-Rajchel, H.; Koroniak, H. Synthesis of 5-fluorovinyl derivatives of pyrimidines via Suzuki-Miyaura coupling and their 1,3-dipolar cycloaddition reactions with nitrones. J. Fluor. Chem. 2012, 135, 225-230. [CrossRef]

34. Mlostoń, G.; Jasiński, M.; Linden, A.; Heimgartner, H. Reactions of 2-Unsubstituted 1H-Imidazole 3-Oxides with 2,2-Bis(trifluoromethyl)ethene-1,1-dicarbonitrile: A Stepwise 1,3-Dipolar Cycloaddition. Helvetica Chimica Acta 2006, 89, 1304-1316. [CrossRef]

35. Jasiński, R. $\beta$-Trifluoromethylated nitroethenes in Diels-Alder reaction with cyclopentadiene: A DFT computational study. J. Fluor. Chem. 2018, 206, 1-7. [CrossRef] 
36. Jasiński, R. Competition between one-step and two-step mechanism in polar [3+2] cycloadditions of (Z)-C-(3,4,5-trimethoxyphenyl)-N-methyl-nitrone with (Z)-2-EWG-1-bromo-1-nitroethenes. Comput. Theor. Chem. 2018, 1125, 77-85. [CrossRef]

37. Jasiński, R.; Dresler, E.; Mikulska, M.; Polewski, D. [3+2] Cycloadditions of 1-halo-1-nitroethenes with (Z)-C-(3,4,5-trimethoxyphenyl)-N-methyl-nitrone as regio- and stereocontrolled source of novel bioactive compounds: Preliminary studies. Curr. Chem. Lett. 2016, 5, 123-128. [CrossRef]

38. Jasiński, R.; Ziółkowska, M.; Demchuk, O.M.; Maziarka, A. Regio- and stereoselectivity of polar [2+3] cycloaddition reactions between (Z)-C-(3,4,5-trimethoxyphenyl)-N-methylnitrone and selected (E)-2-substituted nitroethenes. Cent. Eur. J. Chem. 2014, 12, 586-593. [CrossRef]

39. Jasiński, R. Regio- and stereoselectivity of [2+3]cycloaddition of nitroethene to (Z)-N-aryl-C-phenylnitrones. Collect. Czech. Chem. Commun. 2009, 74, 1341-1349. [CrossRef]

40. Jasiński, R. Selenyl analog of the (Z)-C,N-diphenylnitrone as the TAC in [3+2] cycloaddition with nitroethene: A DFT computational study. Phosphorus Sulfur Silicon Relat. Elem. 2020, 195, 871-876. [CrossRef]

41. Kula, K.; Łapczuk-Krygier, A. A DFT computational study on the [3+2] cycloaddition between parent thionitrone and nitroethene. Curr. Chem. Lett. 2018, 7, 27-34. [CrossRef]

42. Jasiński, R. A stepwise, zwitterionic mechanism for the 1,3-dipolar cycloaddition between (Z)-C-4-methoxyphenyl-N-phenylnitrone and gem-chloronitroethene catalysed by 1-butyl-3-methylimidazolium ionic liquid cations. Tetrahedron Lett. 2015, 56, 532-535. [CrossRef]

43. Jasiński, R. First example of stepwise, zwitterionic mechanism for bicyclo[2.2.1]hept-5-ene (norbornene) formation process catalyzed by the 1-butyl-3-methylimidazolium cations. Monatshefte für Chemie 2016, 147, 1207-1213. [CrossRef]

44. Jasiński, R. Competition between the one-step and two-step, zwitterionic mechanisms in the [2+3] cycloaddition of gem-dinitroethene with (Z)-C, N-diphenylnitrone: A DFT computational study. Tetrahedron 2013, 69, 927-932. [CrossRef]

45. Tartakovskii, V.A.; Sebastianova, I.A.; Novikov, S.S. О-метиловый зчир нитродиметилмалоната вреакции1,3-диполярноgо циклоприсоединения. Zhurnal Obshchei Khimii 1968, 4, 240-243.

46. Kącka-Zych, A. Push-pull nitronates in the 32CAwith nitroethylene: Molecular Electron Density Theory study. J. Mol. Graph. Model. 2020, 97, 107549. [CrossRef] [PubMed]

47. Loska, R.; Mąkosza, M. Simple method for the introduction of tetrafluoroethyl substituents into nitrogen heterocycles. Mendeleev Commun. 2006, 16, 161-163. [CrossRef]

48. Jin, H.; Rudolph, M.; Rominger, F.; Hashmi, A.S.K. The Carbocation-Catalyzed Intermolecular Formal [2+2+1] Cycloaddition of Ynamides with Quinoxaline N-Oxides. ACS Catal. 2019, 9, 11663-11668. [CrossRef]

49. Cramer, C.J. Essentials of Computational Chemistry. Theories and Models; Wiley: Chichester, UK, 2002; pp. 121-152.

50. Elender, K.; Riebel, P.; Weber, A.; Sauer, J. 1,3-Dipolar Cycloaddition Reactions of Stable Bicyclic and Monocyclic Azomethine Ylides: Kinetic Aspects. Tetrahedron 2000, 56, 4261-4265. [CrossRef]

51. Domingo, L.R.; Kula, K.; Ríos-Gutiérrez, M. Unveiling the Reactivity of Cyclic Azomethine Ylides in 32CAReactions within the Molecular Electron Density Theory. Eur. J. Org. Chem. 2020, 37, 5938-5948.

52. Mloston, G.; Urbaniak, K.; Domagała, M. Thermal [2+3]-Cycloadditions of trans-1-Methyl-2,3-diphenylaziridine with $\mathrm{C}=\mathrm{S}$ and $\mathrm{C}=\mathrm{C}$ Dipolarophiles: An Unexpected Course with Dimethyl Dicyanofumarate. Helvetica Chimica Acta 2009, 92, 2631-2642. [CrossRef]

53. Żmigrodzka, M.; Dresler, E.; Hordyjewicz-Baran, Z.; Kulesza, R.; Jasiński, R. A unique example of noncatalyzed 32CAinvolving (2E)-3-aryl-2-nitroprop-2-enenitriles. Chem. Heterocycl. Compd. 2017, 53, 1161-1162. [CrossRef]

54. Jasiński, R.; Kula, K.; Kacka, A.; Mirosław, B. Unexpected course of reaction between (E)-2-aryl-1-cyano-1-nitroethenes and diazafluorene: Why is there no 1,3-dipolar cycloaddition? Monatshefte für Chemie 2017, 148, 909-915. [CrossRef]

55. Beltrame, P.; Sartirana, P.; Vintani, C. Relative rates of the concurrent reactions in the addition of a substituted benzonitrile oxide to arylacetylenes. J. Chem. Soc. B 1971, 814-817. [CrossRef]

56. Dondoni, A.; Barbaro, G. Kinetics of addition and cycloaddition of phenylacetylene to benzonitrile N-oxides. Competitive concerted and stepwise mechanisms. J. Chem. Soc. Perkin Trans. 1974, 1591-1594. [CrossRef]

57. Baran, J.; Mayr, H. Mechanistic impact of oxime formation accompanying 1,3-dipolar cycloadditions of nitrile oxides. J. Org. Chem. 1989, 54, 5012-5016. [CrossRef] 
58. Jasiński, R. Nitroacetylene as dipolarophile in [2+3] cycloaddition reactions with allenyl-type three-atom components: DFT computational study. Monatshefte für Chemie 2015, 146, 591-599. [CrossRef] [PubMed]

59. Siadati, S.A. An example of a stepwise mechanism for the catalyst-free 1,3-dipolar cycloaddition between a nitrile oxide and an electron rich alkene. Tetrahedron Lett. 2015, 56, 4857-4863. [CrossRef]

60. Siadati, S.A. The Effect of Position Replacement of Functional Groups on the Stepwise character of 1,3-Dipolar Reaction of a Nitrile Oxide and an Alkene. Helv. Chim. Acta 2016, 99, 273-280. [CrossRef]

61. Quast, H.; Regnat, D.; Peters, E.M.; Peters, K.; von Schnering, H.G. Zwitterions as Intermediates of the 1,3-Dipolar Cycloaddition of Electrophilic Azides to 5-Alkylidenedihydrotetrazoles-the Other Non-Concerted Limiting Case. Angew. Chem. Int. Ed. EngI. 1990, 29, 695-697. [CrossRef]

62. Quast, H.; Ach, M.; Ivanova, S.; Peters, I.K.; von Schnering, H.G. Zwitterions as Intermediates in 1,3-Dipolar Cycloadditions of Electrophilic Azides to 2-Alkylidenetetrahydroimidazoles and 2-Alkylidenedihydrobenzimidazoles. Liebigs Ann. 1996, 1996, 1551-1558. [CrossRef]

63. Shimizu, N.; Bartlett, P.D.; Worth, F. Cycloaddition of Diazoalkanes to Penta- and Hexafluoroacetones. Isolation of A 3 -1,3,4-Oxadiazolines and Their Decomposition via Carbonyl Ylides. J. Am. Chem. Soc. 1978, 100, 4260-4267. [CrossRef]

64. Jasiński, R. On the question of zwitterionic intermediates in 1,3-dipolar cycloadditions between hexafluoroacetone and sterically crowded diazocompounds. J. Fluor. Chem. 2015, 176, 35-39. [CrossRef]

65. Mlostoń, G.; Celeda, M.; Jasiński, R.; Heimgartner, H. Experimental and Computational Studies on Stepwise [3+2]-Cycloadditions of Diaryldiazomethanes with Electron-Deficient Dimethyl (E)- and (Z)-2,3-Butenedioates. Eur. J. Org. Chem. 2019, 2019, 422-431. [CrossRef]

66. Mlostoń, G.; Jasiński, R.; Kula, K.; Heimgartner, H. A DFT Study on the Barton-Kellogg Reaction-The Molecular Mechanism of the Formation of Thiiranes in the Reaction between Diphenyldiazomethane and Diaryl Thioketones. Eur. J. Org. Chem. 2020, 2020, 176-182. [CrossRef]

67. Huisgen, R.; Langhals, E. 1,3-Dipolar cycloadditions of diphenyldiazomethane to thioketones: Rate measurements disclose thiones to be superdipolarophiles. Heteroat. Chem. 2006, 17, 433-442. [CrossRef]

68. Mlostoń, G.; Urbaniak, K.; Pawlak, A.; Heimgartner, H. New Applications of Hetaryl Thioketones for the Synthesis of Hetaryl-Substituted Ethenes via 'Two-Fold Extrusion Reaction. Heterocycles 2016, 93, 127-139.

Publisher's Note: MDPI stays neutral with regard to jurisdictional claims in published maps and institutional affiliations.

(C) 2020 by the authors. Licensee MDPI, Basel, Switzerland. This article is an open access article distributed under the terms and conditions of the Creative Commons Attribution (CC BY) license (http://creativecommons.org/licenses/by/4.0/). 